\title{
Genetic Diversity of Verticillium dahliae Populations From Olive and Potato in Lebanon
}

\author{
Farah Baroudy, ${ }^{1,2}$ Alexander I. Putman, ${ }^{3}$ Wassim Habib, ${ }^{2}$ Krishna D. Puri, ${ }^{4}$ Krishna V. Subbarao, ${ }^{4}$ and Franco Nigro ${ }^{1, \dagger}$ \\ ${ }^{1}$ Dipartimento di Scienze del Suolo, Università degli Studi di Bari - Aldo Moro, Bari, 70126 Bari, Italy; ${ }^{2}$ Lebanese Agricultural \\ Research Institute, Laboratory of Mycology, Department of Plant Protection, Fanar, Jdeidet El Metn, Lebanon; ${ }^{3}$ Department of \\ Microbiology and Plant Pathology, University of California, Riverside, CA 92521, U.S.A.; and ${ }^{4}$ Department of Plant Pathology, \\ University of California, Davis, c/o U.S. Agricultural Research Station, Salinas, CA 93905, U.S.A.
}

\begin{abstract}
Verticillium dahliae is widely distributed in potato and olive fields in Lebanon, causing serious economic losses. However, little is known about the inoculum source, population structure, and genetic diversity of the pathogen or the mechanisms of dissemination within Lebanon. To understand the population structure, a total of 203 isolates sampled from olive $(n=78)$ and potato $(n=125)$ were characterized for species, mating type, and race, and the genetic relationships were delineated using 13 microsatellite markers. All isolates except one from potato were $V$. dahliae, with 55.1 and $12.1 \%$ race 1 , and 43.6 and $83.1 \%$ race 2 in olive and potato, respectively. The genetic structure of the studied

population was best described by two large and two small clusters. Membership in the two large clusters was determined by the presence or absence of the effector gene Ave1. Furthermore, genetic structure was moderately associated with the host of origin but was weakly associated with the geographic origin. All but four isolates represented by three multilocus haploid genotypes were MAT1-2. This study identified a clear lack of gene flow between virulence genotypes of $V$. dahliae despite the proximity of these cropping systems and the wide distribution of genetic diversity among hosts and geographic regions in Lebanon.
\end{abstract}

Potato and olive represent two of the most important sources of sustenance and income in Lebanon. Potato ranked first with a total production of 443,000 tons from a 17,352-ha area in 2014 (FAOSTAT 2014). Olive has been cultivated in Lebanon for thousands of years (Chalak et al. 2015), and in 2014 was produced on 58,496 ha (FAOSTAT 2014). Overall potato production is concentrated in Bekaa (70\%) and Akkar (27\%) districts, whereas olive production is spread among North Lebanon (23\%), Nabatiyeh (21\%), Akkar (18\%), and South Lebanon (15\%). In the last decade, a gradual increase in area under olive cultivation has expanded into Bekaa (Anonymous 2012).

Verticillium dahliae Kleb. causes vascular wilts of nearly 200 plant species (Inderbitzin and Subbarao 2014), including olive and potato. $V$. dahliae is a soil-borne fungus that produces microsclerotia that survive in soil for at least 14 years (Wilhelm 1955). As a result, once microsclerotia infest the soil and increase to thresholds that affect different crops, control of Verticillium wilt is difficult. Verticillium wilt causes billions of dollars of damage annually to a variety of crops throughout the world (Pegg and Brady 2002). Recent surveys indicated high incidence of Verticillium wilt in both olive (25.7\%) and potato (61.2\%) fields in Lebanon, and were widely distributed among fields (46.2 and $77.5 \%$, respectively) (Baroudy et al. 2016; Habib et al. 2017). However, little information is available on whether the populations from one crop affect the other and the structure of these populations. Knowledge of the genetic structure of $V$. dahliae in Lebanon may help explain how the pathogen became widely distributed

${ }^{\dagger}$ Corresponding author: F. Nigro; E-mail: franco.nigro@uniba.it

The first two authors contributed equally to this work and should therefore be considered co-first authors.

*The $\boldsymbol{e}$-Xtra logo stands for "electronic extra" and indicates that two supplementary figures and three supplementary tables are published online.

Accepted for publication 24 September 2018.

() 2019 The American Phytopathological Society on these two crops that are in most cases separated geographically, and would lay the basis for practices to prevent further spread of the pathogen.

Microsatellite markers have been used to characterize the population structure of $V$. dahliae from a single field (Puri et al. 2017) or from a global collection (Short et al. 2015). Microsatellite genotyping was also used to identify clonal lineages in the haploid $V$. dahliae that can help in the determination of several phytopathological traits such as race and pathotype (Rafiei et al. 2018).

First, V. dahliae is known to exhibit qualitative differences in virulence governed by the gene-for-gene interaction between the effector gene Avel in the pathogen and the R gene $\mathrm{Vel}$ in tomato (de Jonge et al. 2012) or its homolog in Solanaceous or non-Solanaceous plants, including potato (Fick and Zimmer 1974; Hayes et al. 2011; Simko et al. 2003; Song et al. 2016; Zhang et al. 2013). Race 1 isolates of $V$. dahliae possess Ave1, the product of which is recognized by hosts with $\mathrm{Vel}$ or a homolog, rendering these isolates avirulent. In contrast, race 2 isolates lack Ave1 and are therefore able to evade recognition and cause disease on hosts with Vel or a homolog. Thus, race is an important context in which to understand the population biology of $V$. dahliae.

Second, the mating type (MAT) locus of $V$. dahliae is organized in a manner typical of heterothallic fungi in which individuals possess only one of the MAT genes MAT1-1-1 or MAT1-2-1, found in the dissimilar idiomorphs MAT1-1 and MAT1-2, respectively. A heterothallic individual generally must encounter an individual of the opposite mating type to sexually reproduce. The meiotic recombination that occurs during sexual reproduction may combine favorable alleles and result in genotypes of the pathogen that are more fit and/or aggressive (Usami et al. 2009). Although no sexual stage has been found in any Verticillium species, the proximity of opposite mating types or their migration into a single field represents a risk of sexual recombination. In addition, there is a lack of information on the distribution of races and mating types among $V$. dahliae isolates within Lebanon. Even though Short et al. (2015) analyzed a global population of over 1,100 isolates from a variety of hosts, isolates from Lebanon were not represented in this study.

The objectives of the present study were to: i) characterize the population genetic structure of $V$. dahliae from olive and potato in Lebanon using microsatellites, mating type, and race designation; and 
ii) determine if this structure is associated with host plant and geographic location of origin.

\section{Materials and Methods}

Isolates collection and DNA extraction. A total of 203 isolates collected from potato plants $(n=125)$ and olive trees $(n=78)$ during nationwide disease surveys in Lebanon were analyzed in this study (Baroudy et al. 2016; Habib et al. 2017). Briefly, both symptomatic and asymptomatic tissue samples from olive trees, and only symptomatic tissue from potato plants were collected from the Northern, Southern, and Bekaa areas in Lebanon. The Northern area consisted of three Lebanese governorates: North Lebanon, Mount Lebanon, and Akkar; the Southern area consisted of South Lebanon and Nabatiyeh governorates; and the Bekaa area included Bekaa and Baalback-Hermel governorates (Table 1). The Verticillium spp. isolates were obtained from the surface-disinfested stem tissue plated on potato dextrose agar (PDA) amended with 500 ppm streptomycin sulfate (Sigma-Aldrich, Milan, Italy). Following isolation of Verticillium from the plated tissue, single conidia cultures were obtained and cultured on PDA for future processing. The single spore cultures were grown in 9-cm PDA plates, parafilmed, and shipped from Italy to Dr. Subbarao's lab at University of California, Davis. Further isolate handling, DNA extraction, and PCR amplification were done following the APHIS permit requirements. All molecular work, unless mentioned otherwise, was done at the University of California, Davis.

For DNA extraction, two or three agar plugs ( $3 \mathrm{~mm}$ diameter) from fresh cultures were transferred to $50 \mathrm{ml}$ of potato dextrose broth and incubated for 10 days at room temperature. Mycelium was collected using vacuum filtration, washed with sterile distilled water, dried using paper towels, and placed in 2-ml tubes for storage at $-80^{\circ} \mathrm{C}$ for later use. Mycelium was then lyophilized and ground to fine powder using FastPrep instrument (MP Biomedicals, Irvine, CA) for $1 \mathrm{~min}$ at maximum speed. The FastDNA Kit (MP Biomedicals LLC, Solon, $\mathrm{OH}$, USA) was used to extract genomic DNA from all isolates following the manufacturer's instructions, and the quality and quantity of DNA were assessed using NanoDrop 1000 spectrophotometer (Thermo Fisher Scientific, Wilmington, DE). An aliquot of the DNA of each isolate was adjusted to $30 \mathrm{ng} / \mu \mathrm{l}$ for all the polymerase chain reactions (PCR).

Verticillium species identification. To identify isolates to species within Verticillium sensu stricto (Inderbitzin et al. 2011), all isolates were tested with previously developed $V$. dahliae $-V$. longisporum multiplex PCR assays (Inderbitzin et al. 2013). Briefly, each PCR reaction consisted of $100 \mathrm{ng}$ DNA, $0.5 \mu \mathrm{M}$ of each primer (D1f/ AlfD1r, A1f/A1r, Df/Dr), and $12.5 \mu \mathrm{l}$ of $2 \times$ GoTaq Green Master Mix (Promega, Madison, WI) in a total volume of $25 \mu$ l. PCR was performed in a ProFlex $2 \times 96$-well PCR System (Thermo Fisher Scientific, Inc.) programmed for $2 \mathrm{~min}$ at $94^{\circ} \mathrm{C}$ for initial denaturation followed by 35 cycles of $10 \mathrm{~s}$ at $94^{\circ} \mathrm{C}, 20 \mathrm{~s}$ at $64^{\circ} \mathrm{C}$, and $1 \mathrm{~min}$ at $72^{\circ} \mathrm{C}$, and a final 7 -min extension at $72^{\circ} \mathrm{C}$. Six microliters of SYBR Gold $1 \times$ (Invitrogen, Carlsbad, CA) was added for each PCR amplicon, loaded to $1.5 \%(\mathrm{wt} / \mathrm{vol})$ agarose gels in $0.5 \% \mathrm{TBE}$ buffer (0.089 M Tris-borate, $0.089 \mathrm{M}$ boric acid, and $0.002 \mathrm{M}$ EDTA) and referenced to 100-bp DNA ladder (Invitrogen Life Technologies, Carlsbad, CA). Gels were run $45 \mathrm{~min}$ at $100 \mathrm{~V}$ and visualized with a transilluminator (UVP, Upland, CA). The band expected for $V$. dahliae is $490 \mathrm{bp}$. Any isolates that did not amplify with the previous multiplex PCR were tested with $V$. nubilum primers (Nuf/NoNuR) using the same PCR mix and conditions described previously for the multiplex (including $0.5 \mu \mathrm{M}$ of each of two primers) except the annealing temperature used was $62^{\circ} \mathrm{C}$.

Mating type determination. A multiplex PCR assay was used to screen for the presence of the mating type genes MAT1-1-1 (primers Alf3/MAT11r) and MAT1-2-1 (primers HMG21f/MAT21r) (Inderbitzin et al. 2011). A 25- $\mu$ l mixture was prepared per DNA sample containing $60 \mathrm{ng}$ genomic DNA, $0.5 \mu \mathrm{M}$ of each primer, and $12.5 \mu 1$ of $2 \times$ GoTaq Green Master Mix. Each PCR had the following thermal profile: $3 \mathrm{~min}$ at $94^{\circ} \mathrm{C}$ for initial denaturation, 35 cycles of $1 \mathrm{~min}$ at $94^{\circ} \mathrm{C}$ for denaturation, $30 \mathrm{~s}$ at $57^{\circ} \mathrm{C}$ for annealing, $1 \mathrm{~min}$ at $72^{\circ} \mathrm{C}$ for extension, and a final 10 min extension at $72^{\circ} \mathrm{C}$. PCR amplicons were visualized as above. The bands expected for MAT11-1 and MAT1-2-1 are $\sim 592 \mathrm{bp}$ and $330 \mathrm{bp}$, respectively.

Race determination. The primers VdAve1F and VdAve1R were used to detect the presence of Ave1, the effector gene possessed by $V$. dahliae race 1 isolates (de Jonge et al. 2012), whereas the VdR2F/ VdR2R primer pair was used to identify race 2 isolates (Short et al. 2014). PCR reactions for race 1 and race 2 were done separately as explained by Gurung et al. (2014). Briefly, each $25 \mu 1$ PCR reaction contained $20 \mathrm{ng}$ genomic DNA, $0.4 \mu \mathrm{M}$ of each primer, and $12.5 \mu \mathrm{l}$ of $2 \times$ GoTaq Green Master Mix. For race 1, each PCR had the following thermal profile: $2 \mathrm{~min}$ at $94^{\circ} \mathrm{C}$ for initial denaturation, followed by 35 cycles of $30 \mathrm{~s}$ at $94^{\circ} \mathrm{C}, 45 \mathrm{~s}$ at $62^{\circ} \mathrm{C}$, and $1 \mathrm{~min}$ at $72^{\circ} \mathrm{C}$ followed by a final extension of $10 \mathrm{~min}$ at $72^{\circ} \mathrm{C}$. For race 2 , each PCR had the following thermal profile: $2 \mathrm{~min}$ at $94^{\circ} \mathrm{C}$ for initial denaturation, followed by 35 cycles of $1 \mathrm{~min}$ at $94^{\circ} \mathrm{C}, 1 \mathrm{~min}$ at $64^{\circ} \mathrm{C}$, and $1 \mathrm{~min}$ at $72^{\circ} \mathrm{C}$ followed by a final extension of $10 \mathrm{~min}$ at $72^{\circ} \mathrm{C}$.

Microsatellite genotyping. Isolates were genotyped using 13 previously described polymorphic microsatellite loci (VD1, VD2, VD3, VD8, VD9, VD10, VD11, VD12, VD27, VD69, VD73, VD92, and VD97) (Molecular Ecology Resources Primer Development Consortium 2009) (Supplementary Table S1). Forward primers were labeled at the $5^{\prime}$ end with one of the following fluorophores: FAM, PET, NED, and VIC. Briefly, PCR was performed in $25 \mu \mathrm{l}$ total volumes containing $8.5 \mu \mathrm{l}$ of sterile distilled water, $2 \mu \mathrm{l}$ of genomic DNA at $30 \mathrm{ng} / \mu \mathrm{l}, 0.5 \mu \mathrm{l}$ of $10 \mu \mathrm{M}$ of each reverse and forward primer, and $12.5 \mu \mathrm{l}$ of GoTaq Colorless Mater Mix (Promega Corp., Madison, WI). PCR was carried out in ProFlex $2 \times 96$-well PCR System (Thermo Fisher Scientific Inc.) that was programmed for $5 \mathrm{~min}$ at $94^{\circ} \mathrm{C}$ for initial denaturation and 35 cycles consisting of $30 \mathrm{~s}$ at $95^{\circ} \mathrm{C}, 20 \mathrm{~s}$ at $55^{\circ} \mathrm{C}$, and $30 \mathrm{~s}$ at $72^{\circ} \mathrm{C}$, followed by a final $10 \mathrm{~min}$ extension at $72^{\circ} \mathrm{C}$. For fragment analysis, the PCR amplicons labeled with different fluorophores (FAM, PET, NED, and VIC) were comigrated by adding $2 \mu \mathrm{l}$ of each labeled PCR product into a 96-well PCR plate. Fragment analysis was performed on an ABI 3100 sequencer (Applied Biosystems, Foster City, CA) at the UC Davis DNA Sequencing Facility following addition of Hi-Di formamide and $0.3 \mu \mathrm{l}$ of LIZ-500 size standard to $1 \mu \mathrm{l}$ of the pooled PCR product. The GeneMarker software (SoftGenetics, State College, PA) was used to determine alleles from the peaks for each fragment. The strain VdLs17 (http://www.broad.mit.edu/annotation/genome/verticillium_ dahliae), for which a complete genome sequence is available, was included in every PCR plate to ensure consistency across runs.

Data analysis. Exploratory analysis of microsatellite allele data

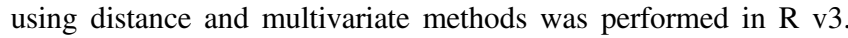
3.2 (R Core Team 2016). First, allele calls and metadata were loaded into $\mathrm{R}$ as a genind object and subjected to quality control steps in the poppr v2.3.0 package (Kamvar et al. 2014, 2015) that removed the VD97 locus and any isolates having more than two missing loci. Other R packages used for minor functions in the analysis pipeline include: cowplot v0.9.3 (Wilke 2018) and fields v8.10 (Nychka et al. 2015) for grouping figures into panels; dplyr v0.5.0 (Wickham and Francois 2016), plyr v1.8.4 (Wickham 2011), stringr v1.3.1 (Wickham 2018), and tidyr v0.6.0 (Wickham 2016) for data manipulation; phangorn v2.4.0 (Schliep 2011) for rooting the distance tree; and RColorBrewer v1.1-2 (Brewer 2013; Neuwirth 2014).

Poppr was used to produce two clone-corrected datasets, consisting of a single allele at each locus for the haploid $V$. dahliae, for downstream population genetic analyses. The first is 'MLG' (multilocus haploid genotype), which was clone-corrected strictly for the 12 microsatellite loci in which missing data serve as an extra allele. However, numerous multilocus genotypes were shared between metadata factors, ensuring that metadata would be lost if isolates were clone-corrected using microsatellite loci only. To associate population genetic data with these factors while still ameliorating the confounding influence of clonality, a second 'MLG+meta' dataset was made that was clone-corrected for the 12 microsatellite loci plus the metadata factors host, geographic region of origin (Bekaa, North, South), and race. For example, an isolate obtained from Bekaa and an isolate obtained from the North region that possess identical alleles at all 12 microsatellite loci would collapse to one multilocus genotype 
Table 1. Isolates of Verticillium dahliae used in this study and their corresponding origin, race, mating type (MAT), idiomorph, and multilocus genotype

\begin{tabular}{|c|c|c|c|c|c|c|}
\hline Isolate & Host & $\begin{array}{c}\text { Geographical } \\
\text { area }^{\mathbf{a}}\end{array}$ & Field & Race $^{\mathbf{b}}$ & $\begin{array}{l}\text { Mating } \\
\text { type }\end{array}$ & $\begin{array}{l}\text { Multilocus } \\
\text { genotype }^{\mathrm{c}}\end{array}$ \\
\hline $\mathrm{O} 1$ & Olive & Bekaa & O-L1 & 2 & MAT1-2-1 & $\mathrm{H} 43$ \\
\hline $\mathrm{O} 2$ & Olive & Bekaa & O-L1 & 2 & $M A T 1-2-1$ & H34 \\
\hline $\mathrm{O} 3$ & Olive & Bekaa & O-L1 & 2 & $M A T 1-2-1$ & H35 \\
\hline $\mathrm{O} 4$ & Olive & Bekaa & O-L1 & 2 & MAT1-2-1 & $\mathrm{H} 43$ \\
\hline O5 & Olive & Bekaa & O-L2 & 2 & $M A T 1-2-1$ & $\mathrm{H} 31$ \\
\hline O6 & Olive & Bekaa & O-L2 & 2 & $M A T 1-2-1$ & $\mathrm{H} 30$ \\
\hline $\mathrm{O} 7$ & Olive & Bekaa & O-L2 & 2 & MAT1-2-1 & $\mathrm{H} 33$ \\
\hline O8 & Olive & Bekaa & O-L2 & 2 & $M A T 1-2-1$ & H33 \\
\hline O9 & Olive & Bekaa & O-L2 & 2 & MAT1-2-1 & $\mathrm{H} 43$ \\
\hline $\mathrm{O} 10$ & Olive & Bekaa & O-L2 & 2 & $M A T 1-2-1$ & $\mathrm{H} 43$ \\
\hline O11 & Olive & North & O-L4 & 1 & MAT1-2-1 & N.C. \\
\hline $\mathrm{O} 12$ & Olive & North & O-L5 & 1 & $M A T 1-2-1$ & $\mathrm{H} 25$ \\
\hline $\mathrm{O} 13$ & Olive & North & O-L5 & 1 & MAT1-2-1 & $\mathrm{H} 25$ \\
\hline $\mathrm{O} 14$ & Olive & North & O-L6 & 2 & $M A T 1-2-1$ & $\mathrm{H} 43$ \\
\hline $\mathrm{O} 15$ & Olive & North & O-L9 & 2 & $M A T 1-2-1$ & N.C. \\
\hline $\mathrm{O} 17$ & Olive & Bekaa & O-L10 & 2 & $M A T 1-2-1$ & H6 \\
\hline O19 & Olive & Bekaa & O-L10 & N.A. & MAT1-2-1 & H12 \\
\hline $\mathrm{O} 20$ & Olive & Bekaa & O-L13 & 1 & $M A T 1-2-1$ & H13 \\
\hline $\mathrm{O} 21$ & Olive & Bekaa & O-L13 & 1 & $M A T 1-2-1$ & N.C. \\
\hline $\mathrm{O} 22$ & Olive & Bekaa & O-L15 & 2 & MAT1-2-1 & $\mathrm{H} 47$ \\
\hline $\mathrm{O} 23$ & Olive & Bekaa & O-L15 & 1 & MAT1-2-1 & H16 \\
\hline $\mathrm{O} 24$ & Olive & Bekaa & O-L15 & 2 & $M A T 1-2-1$ & $\mathrm{H} 50$ \\
\hline $\mathrm{O} 26$ & Olive & Bekaa & O-L15 & 2 & MAT1-2-1 & $\mathrm{H} 43$ \\
\hline $\mathrm{O} 27$ & Olive & Bekaa & O-L16 & 1 & $M A T 1-2-1$ & H17 \\
\hline $\mathrm{O} 28$ & Olive & Bekaa & O-L16 & 1 & MAT1-2-1 & $\mathrm{H} 13$ \\
\hline O29 & Olive & Bekaa & O-L17 & 1 & $M A T 1-2-1$ & H13 \\
\hline $\mathrm{O} 30$ & Olive & Bekaa & O-L18 & 1 & $M A T 1-2-1$ & H13 \\
\hline $\mathrm{O} 31$ & Olive & Bekaa & O-L19 & 2 & MAT1-2-1 & $\mathrm{H} 43$ \\
\hline $\mathrm{O} 33$ & Olive & Bekaa & O-L19 & 2 & MAT1-2-1 & $\mathrm{H} 43$ \\
\hline $\mathrm{O} 34$ & Olive & Bekaa & O-L20 & 1 & MAT1-2-1 & $\mathrm{H} 25$ \\
\hline $\mathrm{O} 35$ & Olive & Bekaa & O-L20 & 1 & MAT1-2-1 & $\mathrm{H} 13$ \\
\hline O36 & Olive & Bekaa & O-L18 & 1 & MAT1-2-1 & H13 \\
\hline $\mathrm{O} 37$ & Olive & Bekaa & O-L22 & 2 & MAT1-2-1 & N.C. \\
\hline $\mathrm{O} 38$ & Olive & Bekaa & O-L22 & 2 & $M A T 1-2-1$ & N.C. \\
\hline O39 & Olive & Bekaa & O-L26 & 2 & $M A T 1-2-1$ & $\mathrm{H} 7$ \\
\hline $\mathrm{O} 42$ & Olive & Bekaa & O-L30 & 2 & MAT1-2-1 & N.C. \\
\hline $\mathrm{O} 43$ & Olive & Bekaa & O-L30 & 1 & MAT1-2-1 & H5 \\
\hline $\mathrm{O} 44$ & Olive & South & O-L32 & 1 & $M A T 1-2-1$ & H13 \\
\hline O45 & Olive & South & O-L32 & 1 & $M A T 1-2-1$ & H54 \\
\hline O46 & Olive & South & O-L34 & 1 & MAT1-2-1 & H13 \\
\hline O47 & Olive & South & O-L35 & 1 & $M A T 1-2-1$ & H13 \\
\hline $\mathrm{O} 48$ & Olive & South & O-L35 & 1 & MAT1-2-1 & H9 \\
\hline $\mathrm{O} 49$ & Olive & South & O-L36 & 2 & $M A T 1-2-1$ & $\mathrm{H} 43$ \\
\hline O50 & Olive & South & O-L37 & 1 & MAT1-2-1 & H19 \\
\hline O51 & Olive & South & O-L37 & 1 & MAT1-2-1 & H11 \\
\hline O52 & Olive & South & O-L44 & 1 & MAT1-2-1 & $\mathrm{H} 13$ \\
\hline O54 & Olive & South & O-L47 & 2 & MAT1-1-1 & $\mathrm{H} 27$ \\
\hline O55 & Olive & North & O-L52 & 1 & MAT1-2-1 & $\mathrm{H} 13$ \\
\hline O56 & Olive & North & O-L52 & 2 & MAT1-2-1 & $\mathrm{H} 43$ \\
\hline O57 & Olive & North & O-L52 & 1 & $M A T 1-2-1$ & H13 \\
\hline O58 & Olive & North & O-L54 & 1 & $M A T 1-2-1$ & $\mathrm{H} 13$ \\
\hline O59 & Olive & North & O-L54 & 1 & MAT1-2-1 & H13 \\
\hline O60 & Olive & North & O-L55 & 2 & $M A T 1-2-1$ & $\mathrm{H} 26$ \\
\hline O62 & Olive & North & O-L56 & 1 & MAT1-2-1 & $\mathrm{H} 10$ \\
\hline O63 & Olive & North & O-L58 & 2 & MAT1-2-1 & $\mathrm{H} 43$ \\
\hline O64 & Olive & North & O-L63 & 2 & MAT1-2-1 & $\mathrm{H} 43$ \\
\hline O65 & Olive & North & O-L51 & 1 & MAT1-2-1 & H13 \\
\hline O66 & Olive & North & O-L51 & 1 & $M A T 1-2-1$ & H13 \\
\hline O67 & Olive & North & O-L57 & 1 & MAT1-2-1 & $\begin{array}{c}\text { N.C. } \\
\text { (Continued) }\end{array}$ \\
\hline
\end{tabular}

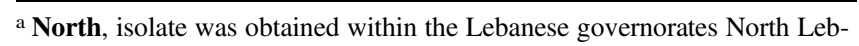
anon, Mount Lebanon, or Akkar. South, from South Lebanon or Nabatiyeh. Bekaa, from Bekaa or Baalback-Hermel.

${ }^{b}$ N.A., did not amplify with either race 1 or race 2 primers pairs.

${ }^{c}$ N.C., isolates removed from SSR analysis due to missing data at more than two loci.
Table 1. (Continued)

\begin{tabular}{|c|c|c|c|c|c|c|}
\hline Isolate & Host & $\begin{array}{l}\text { Geographical } \\
\text { area }^{\mathbf{a}}\end{array}$ & Field & Race $^{\mathbf{b}}$ & $\begin{array}{l}\text { Mating } \\
\text { type }\end{array}$ & $\begin{array}{l}\text { Multilocus } \\
\text { genotype }^{\mathbf{c}}\end{array}$ \\
\hline O68 & Olive & North & O-L59 & 2 & MAT1-2-1 & $\mathrm{H} 43$ \\
\hline $\mathrm{O} 70$ & Olive & South & O-L73 & 2 & MAT1-2-1 & $\mathrm{H} 23$ \\
\hline O71 & Olive & South & O-L75 & 1 & MAT1-2-1 & $\mathrm{H} 13$ \\
\hline $\mathrm{O} 72$ & Olive & South & O-L75 & 1 & MAT1-2-1 & $\mathrm{H} 13$ \\
\hline $\mathrm{O} 73$ & Olive & South & O-L77 & 1 & MAT1-2-1 & H13 \\
\hline O74 & Olive & South & O-L78 & 1 & MAT1-2-1 & H17 \\
\hline $\mathrm{O} 75$ & Olive & South & O-L78 & 1 & MAT1-2-1 & $\mathrm{H} 20$ \\
\hline O76 & Olive & South & O-L79 & 1 & MAT1-2-1 & $\mathrm{H} 18$ \\
\hline O77 & Olive & South & O-L79 & 2 & MAT1-2-1 & H6 \\
\hline $\mathrm{O} 78$ & Olive & South & O-L79 & 1 & MAT1-2-1 & H15 \\
\hline O79 & Olive & South & O-L79 & 1 & MAT1-2-1 & H13 \\
\hline $\mathrm{O} 80$ & Olive & South & O-L81 & 1 & MAT1-2-1 & H13 \\
\hline O81 & Olive & North & O-L85 & 1 & MAT1-2-1 & H13 \\
\hline O82 & Olive & North & O-L105 & 2 & MAT1-1-1 & $\mathrm{H} 28$ \\
\hline $\mathrm{O} 83$ & Olive & Bekaa & O-L120 & 2 & MAT1-2-1 & H46 \\
\hline O85 & Olive & South & O-L129 & 1 & MAT1-2-1 & H18 \\
\hline O86 & Olive & South & O-L130 & 2 & MAT1-2-1 & H43 \\
\hline O87 & Olive & South & O-L130 & 1 & MAT1-2-1 & H13 \\
\hline O88 & Olive & North & O-L132 & 1 & MAT1-2-1 & H19 \\
\hline P89 & Potato & North & NP-L52 & 2 & MAT1-2-1 & H43 \\
\hline P101 & Potato & North & NP-L1 & 2 & MAT1-2-1 & $\mathrm{H} 42$ \\
\hline P102 & Potato & North & NP-L2 & 2 & MAT1-2-1 & H43 \\
\hline P104 & Potato & North & NP-L4 & 2 & MAT1-2-1 & N.C. \\
\hline P105 & Potato & North & NP-L4 & 2 & MAT1-2-1 & $\mathrm{H} 43$ \\
\hline P108 & Potato & North & NP-L14 & 2 & MAT1-2-1 & N.C. \\
\hline P109 & Potato & North & NP-L14 & 2 & MAT1-2-1 & $\mathrm{H} 43$ \\
\hline P110 & Potato & North & NP-L15 & 2 & MAT1-2-1 & $\mathrm{H} 43$ \\
\hline P111 & Potato & North & NP-L15 & 2 & MAT1-2-1 & H36 \\
\hline P113 & Potato & North & NP-L17 & 2 & MAT1-2-1 & H1 \\
\hline P116 & Potato & North & NP-L18 & 2 & MAT1-2-1 & H49 \\
\hline P119 & Potato & North & NP-L20 & 2 & MAT1-2-1 & $\mathrm{H} 43$ \\
\hline P121 & Potato & North & NP-L20 & 2 & MAT1-2-1 & $\mathrm{H} 44$ \\
\hline P127 & Potato & North & NP-L21 & 2 & MAT1-2-1 & $\mathrm{H} 43$ \\
\hline P129 & Potato & North & NP-L21 & 2 & MAT1-2-1 & H41 \\
\hline P136 & Potato & North & NP-L22 & 2 & MAT1-2-1 & H43 \\
\hline P137 & Potato & North & NP-L22 & 2 & MAT1-2-1 & H52 \\
\hline P138 & Potato & North & NP-L24 & 2 & MAT1-2-1 & $\mathrm{H} 43$ \\
\hline P140 & Potato & North & NP-L24 & 2 & MAT1-2-1 & $\mathrm{H} 43$ \\
\hline P142 & Potato & North & NP-L26 & 2 & MAT1-2-1 & H39 \\
\hline P143 & Potato & North & NP-L26 & 2 & $M A T 1-2-1$ & H43 \\
\hline P150 & Potato & North & NP-L27 & 2 & MAT1-2-1 & N.C. \\
\hline P152 & Potato & North & NP-L29 & 2 & MAT1-2-1 & $\mathrm{H} 43$ \\
\hline P153 & Potato & North & NP-L29 & 2 & MAT1-2-1 & $\mathrm{H} 43$ \\
\hline P154 & Potato & North & NP-L36 & 1 & MAT1-2-1 & $\mathrm{H} 22$ \\
\hline P155 & Potato & North & NP-L36 & 1 & MAT1-2-1 & H18 \\
\hline P156 & Potato & North & NP-L37 & 2 & MAT1-2-1 & H43 \\
\hline P157 & Potato & North & NP-L37 & 2 & MAT1-2-1 & $\mathrm{H} 43$ \\
\hline P158 & Potato & North & NP-L38 & 2 & MAT1-2-1 & $\mathrm{H} 43$ \\
\hline P162 & Potato & North & NP-L40 & 2 & MAT1-2-1 & $\mathrm{H} 43$ \\
\hline P166 & Potato & North & NP-L40 & 2 & MAT1-2-1 & $\mathrm{H} 43$ \\
\hline P168 & Potato & North & NP-L41 & 2 & MAT1-1-1 & $\mathrm{H} 27$ \\
\hline P169 & Potato & North & NP-L41 & 2 & MAT1-2-1 & $\mathrm{H} 3$ \\
\hline P175 & Potato & North & NP-L42 & 2 & MAT1-2-1 & $\mathrm{H} 2$ \\
\hline P176 & Potato & North & NP-L46 & 2 & MAT1-2-1 & $\mathrm{H} 43$ \\
\hline P181 & Potato & South & SP-L1 & 2 & MAT1-2-1 & $\mathrm{H} 43$ \\
\hline P183 & Potato & South & SP-L1 & N.A. & MAT1-2-1 & $\mathrm{H} 4$ \\
\hline P186 & Potato & South & SP-L3 & 2 & MAT1-2-1 & $\mathrm{H} 32$ \\
\hline P191 & Potato & South & SP-L4 & 2 & MAT1-2-1 & H43 \\
\hline P197 & Potato & Bekaa & BP-L3 & 2 & MAT1-2-1 & $\mathrm{H} 43$ \\
\hline P198 & Potato & Bekaa & BP-L3 & 2 & MAT1-2-1 & $\mathrm{H} 43$ \\
\hline P199 & Potato & Bekaa & BP-L5 & 2 & MAT1-2-1 & H45 \\
\hline P203 & Potato & Bekaa & BP-L6 & 2 & MAT1-2-1 & $\mathrm{H} 38$ \\
\hline P205 & Potato & Bekaa & BP-L7 & 2 & MAT1-2-1 & H43 \\
\hline P206 & Potato & Bekaa & BP-L7 & 1 & MAT1-2-1 & H13 \\
\hline P207 & Potato & Bekaa & BP-L8 & 2 & MAT1-2-1 & $\mathrm{H} 29$ \\
\hline P208 & Potato & Bekaa & BP-L8 & 1 & MAT1-2-1 & $\mathrm{H} 20$ \\
\hline & & & & & \multicolumn{2}{|c|}{ (Continued on next page) } \\
\hline
\end{tabular}


Table 1. (Continued from previous page)

\begin{tabular}{|c|c|c|c|c|c|c|}
\hline Isolate & Host & $\begin{array}{c}\text { Geographical } \\
\text { area }^{\mathbf{a}}\end{array}$ & Field & Race $^{b}$ & $\begin{array}{c}\text { Mating } \\
\text { type }\end{array}$ & $\begin{array}{l}\text { Multilocus } \\
\text { genotype }^{c}\end{array}$ \\
\hline P209 & Potato & Bekaa & BP-L9 & 1 & MAT1-2-1 & $\mathrm{H} 24$ \\
\hline P210 & Potato & Bekaa & BP-L9 & 2 & MAT1-2-1 & H55 \\
\hline P214 & Potato & Bekaa & BP-L10 & 2 & MAT1-2-1 & H55 \\
\hline P215 & Potato & Bekaa & BP-L11 & 2 & MAT1-2-1 & $\mathrm{H} 40$ \\
\hline P216 & Potato & Bekaa & BP-L11 & 2 & MAT1-2-1 & $\mathrm{H} 43$ \\
\hline P217 & Potato & Bekaa & BP-L12 & 2 & MAT1-2-1 & $\mathrm{H} 43$ \\
\hline P219 & Potato & Bekaa & BP-L12 & 2 & MAT1-2-1 & $\mathrm{H} 40$ \\
\hline P220 & Potato & Bekaa & BP-L13 & 1 & MAT1-2-1 & H13 \\
\hline P222 & Potato & Bekaa & BP-L13 & 1 & MAT1-2-1 & $\mathrm{H} 21$ \\
\hline P223 & Potato & Bekaa & BP-L14 & 2 & MAT1-2-1 & $\mathrm{H} 43$ \\
\hline P225 & Potato & Bekaa & BP-L14 & 2 & MAT1-2-1 & H43 \\
\hline P227 & Potato & Bekaa & BP-L15 & 1 & MAT1-2-1 & H14 \\
\hline P228 & Potato & Bekaa & BP-L16 & 2 & MAT1-2-1 & $\mathrm{H} 43$ \\
\hline P230 & Potato & Bekaa & BP-L16 & 2 & MAT1-2-1 & $\mathrm{H} 43$ \\
\hline P231 & Potato & Bekaa & BP-L17 & 1 & MAT1-2-1 & H13 \\
\hline P234 & Potato & Bekaa & BP-L19 & 2 & $M A T 1-2-1$ & $\mathrm{H} 43$ \\
\hline P235 & Potato & Bekaa & BP-L20 & 2 & MAT1-2-1 & H55 \\
\hline P236 & Potato & Bekaa & BP-L20 & 2 & MAT1-2-1 & H43 \\
\hline P244 & Potato & Bekaa & BP-L23 & 2 & $M A T 1-2-1$ & H43 \\
\hline P245 & Potato & Bekaa & BP-L23 & 1 & MAT1-2-1 & $\mathrm{H} 20$ \\
\hline P248 & Potato & Bekaa & BP-L24 & 2 & MAT1-2-1 & N.C. \\
\hline P249 & Potato & Bekaa & BP-L24 & 1 & MAT1-2-1 & $\mathrm{H} 25$ \\
\hline P254 & Potato & Bekaa & BP-L26 & 2 & MAT1-2-1 & H43 \\
\hline P256 & Potato & Bekaa & BP-L26 & 1 & MAT1-2-1 & H13 \\
\hline P259 & Potato & Bekaa & BP-L27 & 2 & MAT1-2-1 & $\mathrm{H} 43$ \\
\hline P260 & Potato & Bekaa & BP-L28 & 2 & MAT1-2-1 & H43 \\
\hline P263 & Potato & Bekaa & BP-L29 & 2 & MAT1-2-1 & $\mathrm{H} 43$ \\
\hline P265 & Potato & Bekaa & BP-L29 & 2 & MAT1-2-1 & H44 \\
\hline P267 & Potato & Bekaa & BP-L30 & 2 & MAT1-2-1 & H55 \\
\hline P268 & Potato & Bekaa & BP-L31 & 2 & MAT1-2-1 & $\mathrm{H} 43$ \\
\hline P281 & Potato & Bekaa & BP-L34 & 2 & MAT1-2-1 & $\mathrm{H} 43$ \\
\hline P282 & Potato & Bekaa & BP-L34 & 1 & MAT1-1-1 & H8 \\
\hline P284 & Potato & Bekaa & BP-L35 & 2 & MAT1-2-1 & H53 \\
\hline P285 & Potato & Bekaa & BP-L36 & 2 & MAT1-2-1 & H43 \\
\hline P287 & Potato & Bekaa & BP-L36 & 2 & $M A T 1-2-1$ & H43 \\
\hline P288 & Potato & Bekaa & BP-L36 & 2 & MAT1-2-1 & H43 \\
\hline P292 & Potato & Bekaa & BP-L37 & N.A. & MAT1-2-1 & N.C. \\
\hline P293 & Potato & Bekaa & BP-L38 & 2 & $M A T 1-2-1$ & H43 \\
\hline P296 & Potato & Bekaa & BP-L39 & 2 & MAT1-2-1 & H43 \\
\hline P300 & Potato & Bekaa & BP-L40 & 2 & MAT1-2-1 & H36 \\
\hline P301 & Potato & Bekaa & BP-L50 & 2 & MAT1-2-1 & H55 \\
\hline P302 & Potato & Bekaa & BP-L50 & N.A. & MAT1-2-1 & H48 \\
\hline P307 & Potato & Bekaa & BP-L53 & 2 & MAT1-2-1 & H43 \\
\hline P311 & Potato & Bekaa & BP-L55 & 1 & MAT1-2-1 & H53 \\
\hline P315 & Potato & Bekaa & BP-L58 & 2 & MAT1-2-1 & H43 \\
\hline P316 & Potato & Bekaa & BP-L58 & 2 & MAT1-2-1 & H55 \\
\hline P317 & Potato & Bekaa & BP-L58 & 2 & MAT1-2-1 & H55 \\
\hline P318 & Potato & Bekaa & BP-L59 & 2 & MAT1-2-1 & H46 \\
\hline P319 & Potato & Bekaa & BP-L59 & N.A. & MAT1-2-1 & H43 \\
\hline P321 & Potato & Bekaa & BP-L61 & 1 & MAT1-2-1 & H13 \\
\hline P324 & Potato & Bekaa & BP-L61 & 2 & MAT1-2-1 & H43 \\
\hline P326 & Potato & Bekaa & BP-L62 & 2 & MAT1-2-1 & H37 \\
\hline P327 & Potato & Bekaa & BP-L63 & 2 & MAT1-2-1 & H51 \\
\hline P328 & Potato & Bekaa & BP-L64 & 2 & MAT1-2-1 & N.C. \\
\hline P329 & Potato & Bekaa & BP-L65 & 2 & MAT1-2-1 & H43 \\
\hline P334 & Potato & Bekaa & BP-L1 & 2 & MAT1-2-1 & H43 \\
\hline P338 & Potato & Bekaa & BP-L2 & 2 & MAT1-2-1 & H52 \\
\hline P341 & Potato & Bekaa & BP-L2 & 2 & MAT1-2-1 & H43 \\
\hline P347 & Potato & Bekaa & BP-L4 & 2 & MAT1-2-1 & $\mathrm{H} 40$ \\
\hline P348 & Potato & Bekaa & BP-L4 & 2 & MAT1-2-1 & H44 \\
\hline P356 & Potato & Bekaa & BP-L41 & 2 & MAT1-2-1 & H43 \\
\hline P357 & Potato & Bekaa & BP-L42 & 2 & MAT1-2-1 & H43 \\
\hline P360 & Potato & Bekaa & BP-L42 & 2 & MAT1-2-1 & H43 \\
\hline P362 & Potato & Bekaa & BP-L43 & 2 & MAT1-2-1 & H43 \\
\hline P364 & Potato & Bekaa & BP-L43 & N.A. & MAT1-2-1 & H43 \\
\hline P366 & Potato & Bekaa & BP-L44 & 2 & MAT1-2-1 & $\begin{array}{c}\mathrm{H} 43 \\
(\text { Continued })\end{array}$ \\
\hline
\end{tabular}

Table 1. (Continued)

\begin{tabular}{llccccc}
\hline Isolate & Host & $\begin{array}{c}\text { Geographical } \\
\text { area }^{\mathbf{a}}\end{array}$ & Field & Race $^{\text {b }}$ & $\begin{array}{c}\text { Mating } \\
\text { type }\end{array}$ & $\begin{array}{c}\text { Multilocus } \\
\text { genotypec }^{\mathbf{c}}\end{array}$ \\
\hline P367 & Potato & Bekaa & BP-L44 & 2 & MAT1-2-1 & H55 \\
P368 & Potato & Bekaa & BP-L45 & N.A. & MAT1-2-1 & H56 \\
P369 & Potato & Bekaa & BP-L45 & 2 & MAT1-2-1 & H43 \\
P373 & Potato & Bekaa & BP-L46 & 2 & MAT1-2-1 & H43 \\
P374 & Potato & Bekaa & BP-L47 & 2 & MAT1-2-1 & H43 \\
P375 & Potato & Bekaa & BP-L47 & 2 & MAT1-2-1 & N.C. \\
P376 & Potato & Bekaa & BP-L48 & 2 & $M A T 1-2-1$ & H43 \\
P377 & Potato & Bekaa & BP-L48 & 2 & $M A T 1-2-1$ & N.C. \\
P378 & Potato & Bekaa & BP-L49 & 2 & $M A T 1-2-1$ & H43 \\
P381 & Potato & Bekaa & BP-L49 & 2 & $M A T 1-2-1$ & N.C. \\
P383 & Potato & Bekaa & BP-L51 & 2 & $M A T 1-2-1 ~$ & H39 \\
\hline
\end{tabular}

in the MLG dataset and two multilocus genotypes in the MLG+meta dataset. Mating type was not included in this clone-correction because all but a few isolates were of one mating type. For the MLG dataset, a minimum spanning network of Bruvo's genetic distance (Bruvo et al. 2004) was calculated using the bruvo.msn function in poppr. The network was visualized using the layout_with_kk function in the package igraph v1.2.1 (Csardi and Nepusz 2006), with the Kamada-Kawai vertex attraction constant (kkconst) set at 58 to reduce crossing edges, and the ggnetwork function in the package ggnetwork v0.5.1 (Briatte 2016). The network was annotated with the distribution of levels of metadata factors (host, geographic region of origin, and race) among isolates within each multilocus genotype using the geom_scatterpie function of the scatterpie v0.1.2 package (Yu 2018). To allow support of edges in this network to be evaluated, a neighbor-joining tree with 1,000 bootstrap replicates was constructed from the MLG dataset using the bruvo.boot function in poppr, with bootstrap values $<50$ discarded. Several branches with negative lengths were changed to zero. The tree was visualized using the package ggtree v1.10.5 (Yu et al. 2017).

Next, discriminant analysis of principal components (DAPC) (Jombart et al. 2010) was performed on the 'MLG+meta' dataset using the adegenet package v2.0.1 (Jombart 2008; Jombart and Ahmed 2011). DAPC consists of three steps: 1) principal components analysis (PCA); 2) assigning individuals to groups; and 3) discriminant analysis to summarize structure among groups. Here, two DAPC analyses were formed in parallel that used either unsupervised $k$-means clustering or the metadata factors for the group assignment step. For $k$-means clustering, the function find.clusters was run 10 replicate times with the parameters max.n.clust $=20$, n.iter $=100,000$, n.start $=50$ to infer the optimal number of clusters to describe the data as measured by Bayesian information criterion. Next, a single run of find.clusters was performed with the chosen optimal number of clusters n.clust $=4$ (Supplementary Fig. S1) to assign individuals to groups for the DAPC step. For the second parallel analysis, the metadata factors used for a priori group assignment were host, geographic region, race, and host-region, host-race, region-race combined factors. To compare these two analyses and visually determine how well the population structure can be summarized by metadata factors, the results from the $k$-means analysis was color coded according to each of the six metadata factors or combinations. Thus, the $k$-means clustering analysis consisted of one cluster analysis, whereas the metadata group assignment consisted of six separate analyses. For the DAPC step, the number of principal component axes needed to reach $90 \%$ of variation was retained, and up to three discriminant axes were retained in each analysis. To compare this analysis with the Bruvo's distance described above, the $k$-means cluster assignment of each MLG was visualized on the minimum spanning network.

Based on this exploratory analysis, further analysis was performed on the host and race metadata factor groups as well as the $k$-means clusters from the DAPC analysis. To assess allelic diversity, two measures of richness and two measures of heterogeneity were calculated for all three datasets (full, MLG+meta, MLG). Allelic richness measures were: $A_{R}$ (allelic richness), which was calculated with 
rarefaction to the smallest sample size across all populations and loci within each metadata factor using the allel.rich command in the $\mathrm{R}$ package PopGenReport v3.0.0 (Adamack and Gruber 2014); and $\mathrm{N}_{\mathrm{p}}$ (number of private alleles), which was determined with the private_alleles command in poppr. Allelic heterogeneity measures were calculated using the 'HDP' panel in GenAlEx v6.503 (Peakall and Smouse 2006, 2012) and consisted of: I (information index), which is analogous to H' (Shannon-Wiener Index) in ecology; and $\mathrm{N}_{\mathrm{e}}$ (number of effective alleles). In addition, the allelic heterogeneity measure I (information index) was calculated for each locus of the MLG+meta dataset using the 'HDL' panel in GenAlEx.

To assess multilocus genotype diversity, one measure of clonal richness, two measures of richness, two measures of heterogeneity, and one measure of evenness were calculated for the full 186 isolate
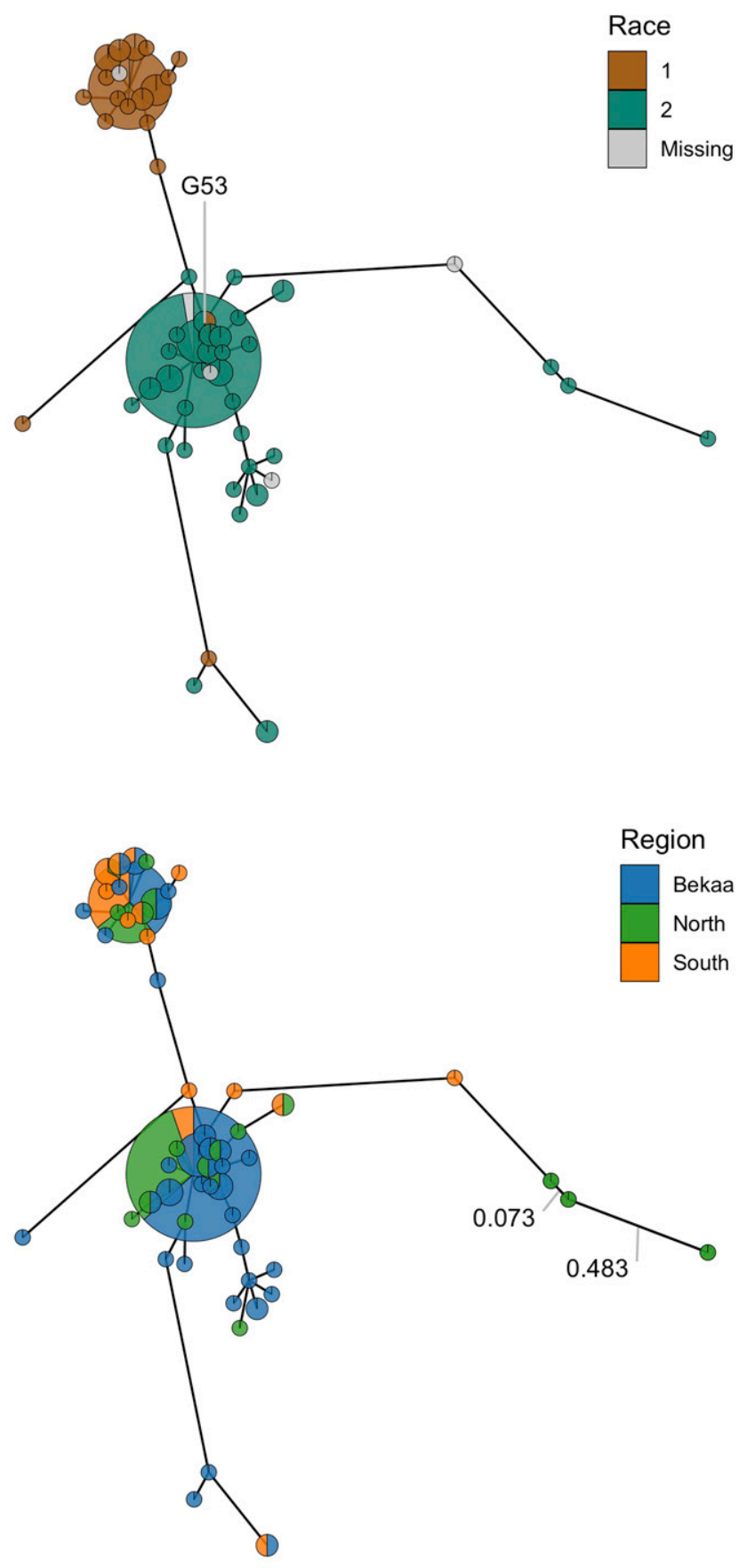

dataset manually (clonal richness) or in the poppr package using the poppr command (all other measures). The measures were selected largely based on recommendations by Arnaud-Haond et al. (2007).

The measure of clonal richness used was $\mathrm{R}$, which is modified by Dorken and Eckert (2001) from $P_{d}$ (index of clonal diversity) proposed by Ellstrand and Roose (1987). Haplotype richness measures were: MLG, which is simply the raw number of multilocus genotypes; and eMLG (number of expected multilocus genotypes), which was calculated with rarefaction to the smallest sample size that is $\geq 10$. Genotype heterogeneity measures were: $e^{\mathrm{H}^{\prime}}$, which is $\mathrm{H}^{\prime}$ (Shannon-Wiener Index) converted to the effective number of genotypes, or the number of equally abundant genotypes needed to result in the value of $\mathrm{H}^{\prime}$ calculated from the given population; and $1 / \lambda$ (inverse Simpson's index), which has also been called G
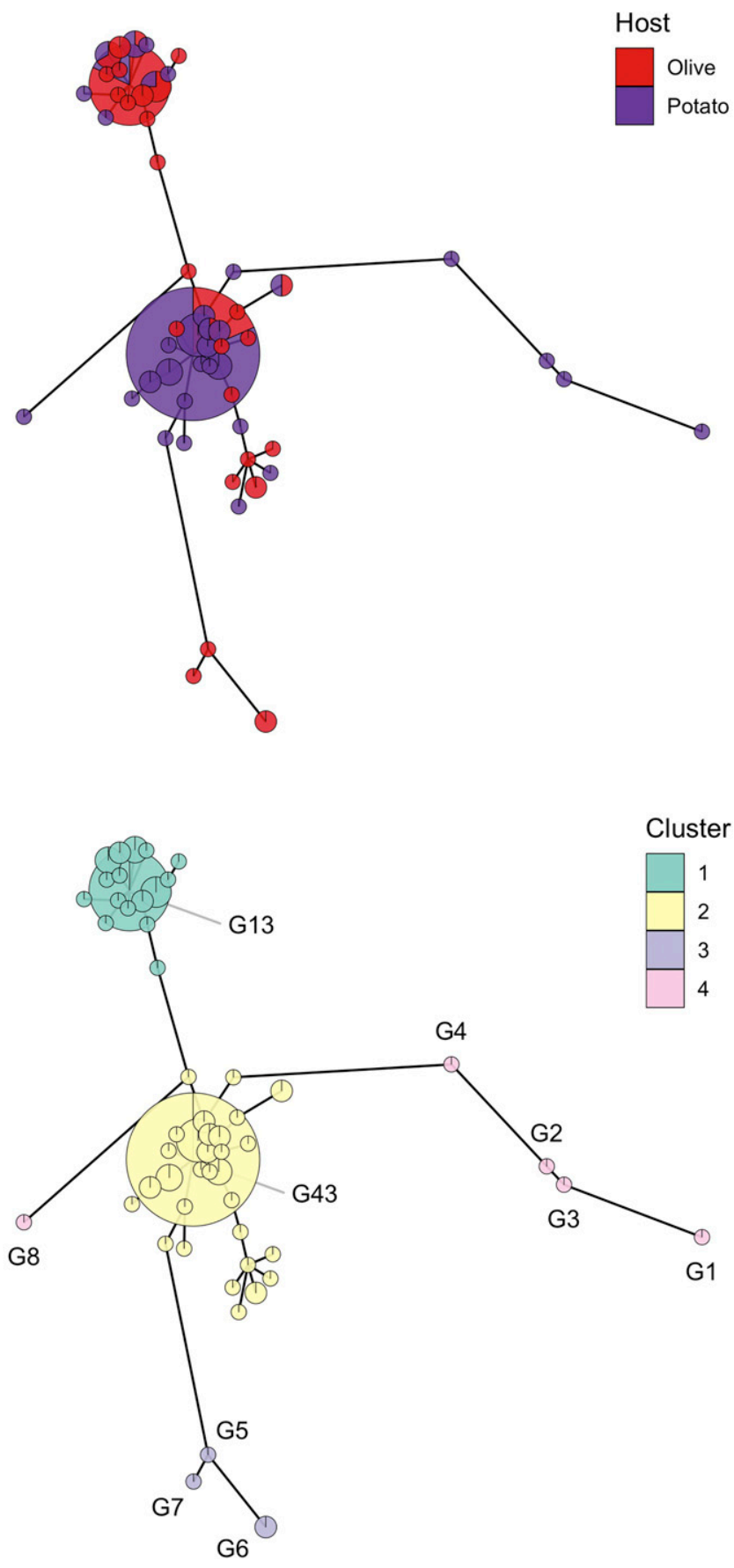

Fig. 1. Minimum spanning network of Verticillium dahliae from Lebanon as inferred by Bruvo's genetic distance. Dataset consisted of 56 multilocus haploid genotypes (MLGs), which was achieved by subjecting raw data to individual (isolates with more than two loci missing removed) and locus (VD97 removed) quality control steps and then strictly clonecorrecting remaining isolates based on alleles at 12 microsatellite loci. Edge length (labeled for two edges in bottom-left Region panel) is proportional to Bruvo's genetic distance. Pies represent MLGs, are centered on nodes of the network, and are annotated with the distribution of isolates among levels of the given metadata factor (race, host, geographic region of origin) or the cluster each MLG was assigned to by $k$-means. Area of pies are scaled to the number of isolates that belong to each MLG ( $G 1=1$ isolate, $G 43=76$ isolates). 
(Stoddart and Taylor's index). The genotype evenness measure was $\mathbf{J}^{\prime}$ (Pielou's evenness), which is also known as the Shannon evenness index or E.5 (modified Hill's evenness). The conversion of an index to an effective number of genotypes, which are also called numbers equivalents or Hill numbers, ameliorates numerous problems with standard diversity indices (Chao et al. 2014; Ellison 2010). For example, indices converted to effective numbers are in the same units as richness measures, thus allowing intuitive comparisons in the form of a $q$ profile (Sherwin et al. 2017). The inverse Simpson index $(1 / \lambda)$ due to its mathematical definition is the effective number conversion of the Gini-Simpson index $(1-\lambda)$ (ArnaudHaond et al. 2007; Chao et al. 2014).
Also from the poppr command, linkage equilibrium was assessed with the null hypothesis of sexual reproduction using 999 permutations of $r_{D}$ (standardized index of association) for the MLG dataset only.

Genetic fixation among clusters, races, hosts, and geographic origins in both the full and clone-corrected MLG+meta datasets was assessed by estimation of the distance-based fixation index $\Phi_{\text {PT }}^{\prime}$, which is standardized for mean within-population diversity (Meirmans 2006), using the analyses of molecular variance (AMOVA) framework (Excoffier et al. 1992; Michalakis and Excoffier 1996). Ф' was calculated via the 'PhiPT' panel in GenAlEx using the 'HaploidSSR' distance measure on raw data with the 'interpolate missing'

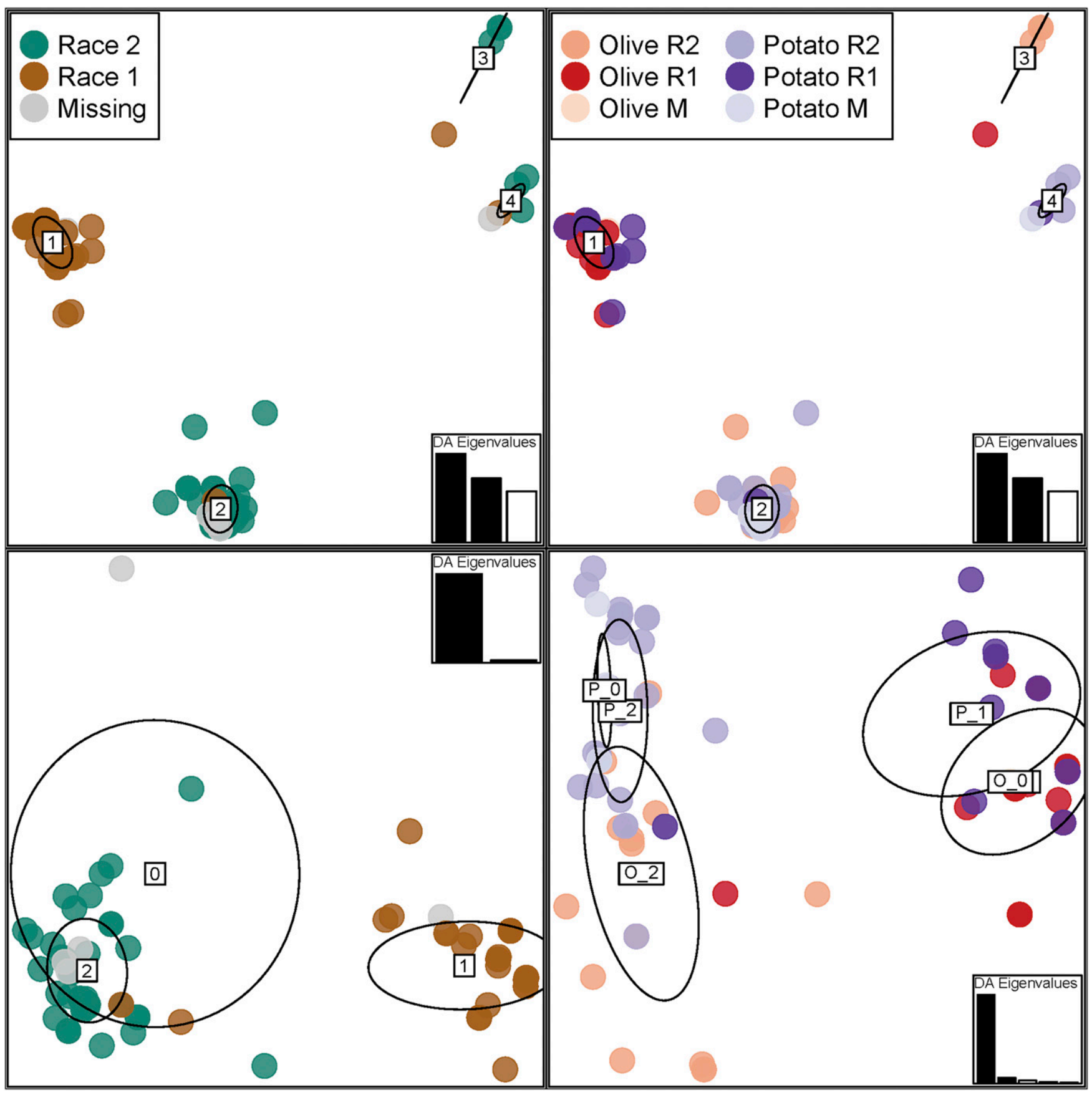

Fig. 2. Association of population structure of Verticillium dahliae with the metadata factors race and combined host of origin and race by discriminant analysis of principal components (DAPC). Dataset was the 79 isolate multilocus haploid genotype (MLG)+meta dataset, which was achieved by subjecting raw data to individual (isolates with more than two loci missing) and locus (VD97 removed) quality control steps and then clone-correcting remaining isolates using 12 microsatellite loci plus the metadata factors host, region, and race. Left column of panels: clones identified by race $\left(0=\right.$ missing). Right column: combined host and race factor $\left(0 \_0=0 l i v e\right.$, race missing; $\mathbf{0} \_1$ = olive race $1 ; \mathbf{0} \_2=$ olive race $2 ; \mathbf{P} \_\mathbf{0}=$ potato, race missing; $\mathbf{P} \_1=$ potato race $1 ; \mathbf{P} \_2=$ potato race 2). Top row of panels: Discriminant analysis (DA) was initialized using an unsupervised $k$-means clustering algorithm at $k=4$. Bottom row: DA was initialized using the respective metadata factor. Ellipses represent variation inertia for each cluster (1-4) or metadata group (e.g., Race 1 or Olive Bekaa). Inset bar charts are scree plots that show eigenvalues of DA axes; shaded bars identify which axes are plotted. 
option selected. Genetic differentiation was assessed by estimation of sH (Shannon information index) (Smouse et al. 2015) in the 'Tot SHT' panel GenAlEx using the log base 2 option. Shannon information complements traditional population genetic indices, and compared with AMOVA indices offers advantages that include greater sensitivity to less frequent alleles, additivity, and allows explicitly hierarchical calculations (Chao et al. 2015; Sherwin et al. 2006, 2017). Both $\Phi_{\text {PT }}^{\prime}$ and sH were estimated using 999 permutations.

\section{Results}

Verticillium species, mating type, and race identification. All isolates included in the study were identified as $V$. dahliae according to the new taxonomic system of classification (Inderbitzin et al. 2011), except for one isolate from potato, which was identified as $V$. nubilum Pethybr. and was therefore excluded for further genotypic study. The majority of $V$. dahliae isolates from olive $(97.4 \%)$ and potato $(98.4 \%)$ amplified a 400 -bp fragment in the MAT-specific PCR assay and were thus designated as MAT1-2-1 mating type. Two isolates from olive (O54 and O82) and two isolates from potato (P168 and P282) amplified a 600-bp band and were considered of MAT11-1 type (Table 1 ).

Out of the $202 \mathrm{~V}$. dahliae isolates analyzed, 137 (67.8\%) belonged to race 2 and $58(28.7 \%)$ to race 1 . PCR products were not obtained from seven isolates (six from potato and one from olive) with either race 1 - or race 2 -specific primers. The frequencies of the two races differed according to the host and geographical origin (Table 1). On olive, $55.1 \%$ of isolates were race 1 and $43.6 \%$ were race 2 , whereas among potato isolates, race $2(83.1 \%)$ was more frequent than race $1(12.1 \%)$. In North and Bekaa, the frequency of race 2 was 73.2 and $74.6 \%$, and that of race 1 was 26.8 and $20.3 \%$, respectively. Conversely, $67.9 \%$ of the isolates were characterized as race 1 and $28.6 \%$ as race 2 in the South.

Microsatellite analysis and data handling. Before quality control, the mean incidence of missing data was 5.8\%. Locus VD97 was discarded due to a high rate of missing data (17.8\%) and because missing data were unevenly concentrated in particular host and geography groups. Other loci with an incidence of missing data above the mean were: VD01 (10.9\%), VD03 (8.9\%), and VD27 (6.9\%). Next, 16 isolates having more than two missing loci were discarded from the dataset, leaving a total of 186 isolates with an overall mean of $2.8 \%$ missing data (Supplementary Tables S2 and S3).

The 'MLG' dataset consisted of 56 MLG, and the 'MLG+meta' dataset consisted of 79 unique combinations of MLGs and the metadata host, geographic region of origin, and race factors. Over half of all isolates in the study belonged to one of two MLGs, G13 (15.1\% of all isolates) and G43 (40.9\%). Haplotypes represented by one isolate covered $21.0 \%$ of the population studied, and MLGs with only two to three isolates representing them belonged to $16.7 \%$ of this population (Table 1).

Population genetic structure. Both DAPC and the minimum spanning network of Bruvo's genetic distance, carried out on the MLG+meta and MLG datasets, respectively, revealed that the genetic structure of $V$. dahliae in Lebanon is best described by four clusters (Figs. 1 and 2). These clusters are comprised of 17, 31, 3, and 5 MLGs (Fig. 1). However, bootstrap values supporting these clusters were generally low $(<50)$ (Supplementary Fig. S2). The minimum spanning network revealed that one genotype in cluster 4, G8, did not 'cluster' with the others, indicating its assignment to that cluster via $k$-means may be the result of the equivalent of long branch attraction. The two abundant genotypes G13 and G43 were assigned to clusters 1 and 2, respectively. The genotype richness of these clusters as measured by eMLG and the genotype heterogeneity as measured by $e^{\mathrm{H}^{\prime}}$ were similar (Table 2). However, $1 / \lambda$, which is more sensitive to abundant genotypes than $e^{\mathrm{H}^{\prime}}$, was slightly lower for cluster 2 compared with cluster 1 , which likely reflects the slightly greater dominance of G43 in cluster 2 compared with G13 in cluster 1 . In the 'MLG' dataset, there was weak evidence for rejection of linkage equilibrium within clusters 1,2 , and $3(P=$ $0.933,0.132$, and 0.644 , respectively), whereas there was

Table 3. Allelic diversity and linkage equilibrium of the multilocus haploid genotype (MLG) dataset

\begin{tabular}{|c|c|c|c|c|c|c|c|}
\hline \multirow[b]{3}{*}{ Factor } & \multirow[b]{3}{*}{ Group } & \multirow[b]{3}{*}{ MLG } & \multicolumn{3}{|c|}{ Allelic diversity } & \multirow{2}{*}{\multicolumn{2}{|c|}{$\begin{array}{c}\begin{array}{c}\text { Linkage } \\
\text { equilibrium }\end{array} \\
r_{D}\end{array}$}} \\
\hline & & & \multirow{2}{*}{$\frac{\text { Richness }^{\mathbf{a}}}{\mathbf{A}_{\mathbf{R}}}$} & \multicolumn{2}{|c|}{ Heterogeneity ${ }^{b}$} & & \\
\hline & & & & I & $\mathbf{N}_{\mathrm{e}}$ & Value & $P<\mathbf{H}_{0}$ \\
\hline \multirow[t]{5}{*}{ Clusters } & 1 & 17 & 13.4 & $0.21(0.09)^{\mathrm{d}}$ & $1.17(0.09)$ & -0.071 & 0.933 \\
\hline & 2 & 31 & 13.9 & $0.32(0.12)$ & $1.26(0.11)$ & 0.032 & 0.132 \\
\hline & 3 & 3 & 13.7 & $0.11(0.08)$ & $1.15(0.10)$ & 0.500 & 0.644 \\
\hline & 4 & 5 & 18.7 & $0.73(0.14)$ & $2.15(0.28)$ & 0.191 & 0.016 \\
\hline & Total & 56 & - & $0.34(0.06)$ & $1.43(0.10)$ & 0.297 & 0.001 \\
\hline
\end{tabular}

a $A_{R}$ : Total allelic richness with rarefaction.

b I: Shannon's information index, $\mathrm{N}_{\mathrm{e}}$ : mean number of effective alleles.

${ }^{\mathrm{c}} \mathrm{r}_{\mathrm{D}}$ : index of association.

${ }^{\mathrm{d}}$ Value in parentheses represents the standard error of the corresponding mean value.

Table 2. Haplotype diversity of Verticillium dahliae from Lebanon using the full dataset

\begin{tabular}{|c|c|c|c|c|c|c|c|c|}
\hline \multirow[b]{2}{*}{ Factor } & \multirow[b]{2}{*}{ Group } & \multirow[b]{2}{*}{ Isolates } & \multirow{2}{*}{$\frac{\text { Cl. Richness }^{\mathbf{a}}}{\mathrm{R}}$} & \multicolumn{2}{|c|}{ Richness $^{\mathbf{b}}$} & \multicolumn{2}{|c|}{ Heterogeneity $^{c}$} & \multirow{2}{*}{$\frac{\text { Evenness }^{\mathbf{d}}}{\mathbf{J}^{\prime}}$} \\
\hline & & & & MLG & eMLG & $e^{\mathbf{H}^{\prime}}$ & $1 / \lambda$ & \\
\hline \multirow[t]{3}{*}{ Host } & Olive & 71 & 0.40 & 29 & $29.0(0.00)^{\mathrm{e}}$ & 13.20 & 6.50 & 0.450 \\
\hline & Potato & 115 & 0.29 & 34 & $24.0(2.18)$ & 8.94 & 3.31 & 0.292 \\
\hline & Total & 186 & 0.30 & 56 & $27.6(2.87)$ & - & - & - \\
\hline \multirow[t]{4}{*}{ Race } & 1 & 55 & 0.33 & 19 & $5.5(1.34)$ & 7.69 & 3.61 & 0.389 \\
\hline & 2 & 125 & 0.27 & 34 & $4.9(1.42)$ & 7.54 & 2.79 & 0.274 \\
\hline & Missing & 6 & 0.80 & 5 & $5.0(0.00)$ & 4.76 & 4.50 & 0.930 \\
\hline & Total & 186 & 0.30 & 56 & $6.1(1.43)$ & - & - & - \\
\hline \multirow[t]{5}{*}{ Cluster } & 1 & 53 & 0.31 & 17 & $5.3(1.31)$ & 6.89 & 3.36 & 0.401 \\
\hline & 2 & 124 & 0.24 & 31 & $4.6(1.40)$ & 6.69 & 2.60 & 0.282 \\
\hline & 3 & 4 & 0.67 & 3 & $3.0(0.00)$ & 2.83 & 2.67 & 0.912 \\
\hline & 4 & 5 & 1.00 & 5 & $5.0(0.00)$ & 5.00 & 5.00 & 1.000 \\
\hline & Total & 186 & 0.30 & 56 & $6.1(1.43)$ & 14.73 & 5.12 & 0.300 \\
\hline
\end{tabular}

a Clonal Richness, R: modified index of clonal diversity.

b MLG: Total number of multilocus haploid genotype (MLG), eMLG: Expected number of MLG at the lowest common sample size within each factor.

${ }^{\mathrm{c}} e^{\mathrm{H}^{\prime}}$ : Shannon-Weiner Diversity index $\left(\mathrm{H}^{\prime}\right)$ converted to a number equivalent (Hill's number) $\left(e^{\mathrm{x}}\right)$, or the effective number of genotypes, $1 / \lambda$ : inverse Simpson index (or G, Stoddart and Taylor index).

d J': Pielou's evenness (or evenness derived from Shannon-Wiener index, E5: Modified Hill's evenness).

e Value in parentheses represents the standard error of the corresponding mean value. 
evidence against linkage equilibrium in cluster $4(P=0.016)$ and in the entire dataset $(P=0.001)$ (Table 3$)$.

Population genetic structure was most strongly associated with race. Except for G53 that belonged to cluster 2 and was shared by one isolate each of race 1 and race 2, all MLG and the major clusters 1 and 2 were fixed for a single race (Table 4 and Fig. 1). A priori initialization of DAPC with the race factor revealed that a large portion of the variation was explained by this factor (Fig. 2). An estimated $41.6 \%$ of molecular variance $(P=0.001)$ (Table 5) and $37.8 \%$ of the Shannon information $(P=0.001)$ was associated with race in the MLG+meta dataset (Table 6). These values were numerically higher in the full dataset (by 27.7 and 18.3 percentage points, respectively), which likely reflects the dominance of the two highly represented G13 and G43 that are fixed for a different race. Haplotype heterogeneity $\left(e^{\mathrm{H}^{\prime}}\right.$ and $\left.1 / \lambda\right)$ was slightly higher among race 1 isolates compared with race 2 (Table 2), which may be reflective of the lower dominance of G13 among race 1 isolates (51\%) compared with G43 among race $2(59 \%)$. Indices of allelic diversity $\left(\mathrm{A}_{\mathrm{R}}, \mathrm{I}\right.$, and $\left.\mathrm{N}_{\mathrm{e}}\right)$ were slightly higher among race 2 isolates compared with race 1 (Table 7).

Exploratory analysis using both DAPC (Figs. 2 and 3) and Bruvo's genetic distance clustering (Fig. 1) revealed a weak to moderate association of host with genetic structure. This structure was confined to a single discriminant axis for the second parallel DAPC analysis initialized using the host factor. Numbers of MLGs and isolates were skewed toward olive in cluster 1 and potato in cluster 2 (Table 4). In particular, $82.1 \%$ of the isolates belonging to G13 are from olive, and
$81.5 \%$ of the isolates belonging to G43 are from potato (Table 1). Although genotype richness was slightly higher and genotype heterogeneity was significantly higher for olive than potato (Table 2), in the MLG+meta dataset allelic richness was higher for potato than olive and heterogeneity for potato was similar to olive (Table 7). For the MLG+meta dataset, a total of 5.5\% $(P=0.015)$ of the observed molecular variance (Table 5) and $11.7 \%(P=0.001)$ of the Shannon information (Table 6) was associated with host of origin. In the full dataset, these values were 18.0 and 6.2 percentage points higher, respectively. This suggests that an appreciable portion of the among-host variation is due to the highly represented G13 and G43 MLGs, which as described above, predominately represent different hosts. In addition, per-locus calculations of the allelic heterogeneity measure I showed that all loci were polymorphic within isolates from potato, whereas isolates from olive were fixed for a single allele at three loci (Table 8).

The abundant G13 and G43 were identified in isolates collected from all three geographic regions (Table 4), and exploratory analyses detected a low degree of structure associated with geography (Figs. 1 and 3). For differentiation in the MLG+meta dataset, $8.4 \%(P=$ 0.017 ) of the observed molecular variance (Table 5) and $11.9 \%$ $(P=0.021)$ of the Shannon information (Table 6$)$ was associated with geographic origin. These values were somewhat higher in the full dataset. In addition to numerical differences between the datasets, the order of factors as determined by among-factor variation is different between the full and MLG+meta datasets. In the MLG+meta dataset, host exhibits the lowest among-factor variation values, whereas geographic origin has the lowest value in the full dataset. This

Table 4. Number of multilocus genotypes (and number of isolates in parentheses) among various factors and population genetic clusters

\begin{tabular}{|c|c|c|c|c|c|c|c|c|c|c|c|}
\hline \multirow[b]{2}{*}{ Factor } & \multicolumn{2}{|c|}{ Host } & \multicolumn{3}{|c|}{ Race } & \multicolumn{2}{|c|}{ Mating type } & \multicolumn{3}{|c|}{ Region } & \multirow[b]{2}{*}{ Total } \\
\hline & Olive & Potato & 1 & 2 & Missing & 1 & 2 & Bekaa & North & South & \\
\hline Olive & - & - & $13(40)$ & $15(30)$ & $1(1)$ & $2(2)$ & $27(69)$ & $17(29)$ & $7(18)$ & $13(24)$ & $29(71)$ \\
\hline Potato & - & - & $10(15)$ & $22(95)$ & $4(5)$ & $2(2)$ & 32 (113) & $23(79)$ & $14(32)$ & $3(4)$ & $34(115)$ \\
\hline Race 1 & - & - & - & - & - & $1(1)$ & $18(54)$ & $23(80)$ & $14(37)$ & $5(8)$ & $34(125)$ \\
\hline Race 2 & - & - & - & - & - & $2(3)$ & $32(122)$ & $11(23)$ & $6(13)$ & $9(19)$ & $19(55)$ \\
\hline Missing & - & - & - & - & - & $0(0)$ & $5(6)$ & $4(5)$ & $0(0)$ & $1(1)$ & $5(6)$ \\
\hline Cluster 1 & $13(40)$ & $8(13)$ & $16(52)$ & $0(0)$ & $1(1)$ & $0(0)$ & $17(53)$ & $9(21)$ & $6(13)$ & 9 (19) & $17(53)$ \\
\hline Cluster 2 & $13(27)$ & $21(97)$ & $1(1)$ & 29 (119) & $3(4)$ & $2(3)$ & $29(121)$ & $23(83)$ & $11(34)$ & $4(7)$ & $31(124)$ \\
\hline Cluster 3 & $3(4)$ & $0(0)$ & $1(1)$ & $2(3)$ & $0(0)$ & $0(0)$ & $3(4)$ & $3(3)$ & $0(0)$ & $1(1)$ & $3(4)$ \\
\hline Cluster 4 & $0(0)$ & $5(5)$ & $1(1)$ & $3(3)$ & $1(1)$ & $1(1)$ & $4(4)$ & $1(1)$ & $3(3)$ & $1(1)$ & $5(5)$ \\
\hline Total $^{\mathrm{a}}$ & $29(71)$ & 34 (115) & $19(55)$ & $34(125)$ & $5(6)$ & $3(4)$ & $53(182)$ & $36(108)$ & $20(50)$ & $15(28)$ & $56(186)$ \\
\hline
\end{tabular}

${ }^{a}$ Within the host, race, and mating type factors, marginal totals may not sum to the actual total number of genotypes because some are shared among multiple levels of a factor.

Table 5. Estimation of $\Phi^{\prime}{ }_{\mathrm{PT}}$ in the analysis of molecular variance framework of Verticillium dahliae isolates in the full and multilocus haploid genotype plus metadata (MLG+meta) datasets grouped by clusters, race, host, and geographic area

\begin{tabular}{|c|c|c|c|c|c|c|c|c|c|}
\hline \multirow[b]{2}{*}{ Factor } & \multirow[b]{2}{*}{ Source } & \multicolumn{4}{|c|}{ Full } & \multicolumn{4}{|c|}{ MLG+meta ${ }^{a}$} \\
\hline & & $\mathbf{d f}^{\mathbf{b}}$ & $\%$ Molecular variance & $\Phi_{\text {PT }}^{\prime}$ & $P>\Phi_{P T}^{\prime}{ }^{c}$ & df & \% Molecular variance & $\Phi_{\text {PT }}^{\prime}$ & $P>\Phi_{\text {PT }}^{\prime}$ \\
\hline \multirow[t]{3}{*}{ Cluster } & Among & 3 & 92.0 & & & 3 & 85.0 & & \\
\hline & Within & 182 & 8.0 & & & 75 & 15.0 & & \\
\hline & Total & 185 & 100.0 & 0.920 & 0.001 & 78 & 100.0 & 0.850 & 0.001 \\
\hline \multirow[t]{3}{*}{ Race } & Among & 2 & 69.3 & & & 2 & 41.6 & & \\
\hline & Within & 183 & 30.7 & & & 76 & 58.4 & & \\
\hline & Total & 185 & 100.0 & 0.693 & 0.001 & 78 & 100.0 & 0.416 & 0.001 \\
\hline \multirow[t]{3}{*}{ Host } & Among & 1 & 23.5 & & & 1 & 5.5 & & \\
\hline & Within & 184 & 76.5 & & & 77 & 94.5 & & \\
\hline & Total & 185 & 100.0 & 0.235 & 0.001 & 78 & 100.0 & 0.055 & 0.015 \\
\hline \multirow[t]{3}{*}{ Geography } & Among & 2 & 16.4 & & & 2 & 8.4 & & \\
\hline & Within & 183 & 83.6 & & & 76 & 91.6 & & \\
\hline & Total & 185 & 100.0 & 0.164 & 0.001 & 78 & 100.0 & 0.084 & 0.022 \\
\hline
\end{tabular}

\footnotetext{
${ }^{a}$ The MLG+meta dataset consisted of clone-correction for the 12 microsatellite loci plus the metadata factors host, geographic region of origin (Bekaa, North, South), and race.

${ }^{\mathrm{b}} \mathrm{df}=$ degrees of freedom.

${ }^{\mathrm{c}}$ The probability of obtaining a random $\Phi_{\text {PT }}$ value greater than the observed data was evaluated by standard permutation over the full dataset.
} 
difference likely reflects the low contribution of clonality to amonggeographic region fixation or differentiation because the highly represented MLGs G13 and G43 were obtained at similar frequencies from all three geographic regions. However, while isolates from the North geographical area belonged to a range of MLGs, approximately two-thirds of MLG representing the Bekaa and South geographical areas were assigned to cluster 2 and cluster 1, respectively (Table 4). Evaluation of pairwise population differentiation using $\Phi^{\prime}{ }_{\text {PT }}$ revealed that the South sampling group was significantly differentiated from the Bekaa group $\left(\Phi_{\text {PT }}^{\prime}=0.186\right)$, but the North group was less differentiated from the South and Bekaa groups (Table 9).

\section{Discussion}

The diversity of Verticillium populations from two strategic cropping systems involving potato and olive in Lebanon were investigated. Except for one isolate, $V$. dahliae was the only species identified on both crops. Races 1 and 2 were detected in both cropping systems but with a higher frequency of race 2 in potato. The MAT1-2 idiomorph was found to be predominant in $V$. dahliae population from Lebanon, in agreement with previous studies from other geographic regions (Dung et al. 2013a; Gurung et al. 2014; Inderbitzin et al. 2011).

Table 6. Shannon Diversity Partition statistics summary table of Verticillium dahliae isolates in the full and multilocus haploid genotype plus metadata (MLG+meta) datasets grouped by clusters, race, host, and geographic area

\begin{tabular}{|c|c|c|c|c|c|c|c|c|c|}
\hline \multirow[b]{2}{*}{ Factor } & \multirow[b]{2}{*}{ Source } & \multicolumn{4}{|c|}{ Full } & \multicolumn{4}{|c|}{ MLG+meta ${ }^{a}$} \\
\hline & & $\overline{d f^{b}}$ & $\mathrm{sH}^{\mathrm{c}}$ & $\% \mathrm{sH}$ & $P>\mathrm{sH}^{\mathrm{d}}$ & df & sH & $\% \mathrm{sH}$ & $P>\mathrm{sH}$ \\
\hline \multirow[t]{3}{*}{ Cluster } & Among & 3 & 0.768 & 79.4 & 0.001 & 3 & 0.910 & 70.7 & 0.001 \\
\hline & Within & 181 & 0.199 & 20.6 & 1.000 & 74 & 0.377 & 29.3 & 1.000 \\
\hline & Total & 184 & 0.966 & 100.0 & & 77 & 1.287 & 100.0 & \\
\hline \multirow[t]{3}{*}{ Race } & Among & 2 & 0.543 & 56.1 & 0.001 & 2 & 0.486 & 37.8 & 0.001 \\
\hline & Within & 182 & 0.424 & 43.9 & 1.000 & 75 & 0.801 & 62.2 & 1.000 \\
\hline & Total & 184 & 0.966 & 100.0 & & 77 & 1.287 & 100.0 & \\
\hline \multirow[t]{3}{*}{ Host } & Among & 1 & 0.173 & 17.9 & 0.001 & 1 & 0.151 & 11.7 & 0.001 \\
\hline & Within & 183 & 0.793 & 82.1 & 1.000 & 76 & 1.136 & 88.3 & 1.000 \\
\hline & Total & 184 & 0.966 & 100.0 & & 77 & 1.287 & 100.0 & \\
\hline \multirow[t]{3}{*}{ Geography } & Among & 2 & 0.127 & 13.1 & 0.001 & 2 & 0.153 & 11.9 & 0.021 \\
\hline & Within & 182 & 0.840 & 86.9 & 1.000 & 75 & 1.134 & 88.1 & 0.980 \\
\hline & Total & 184 & 0.966 & 100.0 & & 77 & 1.287 & 100.0 & \\
\hline
\end{tabular}

a The MLG+meta dataset consisted of clone-correction for the 12 microsatellite loci plus the metadata factors host, geographic region of origin (Bekaa, North, South), and race.

${ }^{\mathrm{b}} \mathrm{df}=$ degrees of freedom

${ }^{c} \mathrm{sH}=$ Shannon information.

$\mathrm{d}$ The probability of obtaining a random $\mathrm{sH}$ value greater than the observed data was evaluated by standard permutation over the full dataset.
This study revealed that genetic structure in $V$. dahliae in Lebanon is strongly associated with the presence or absence of its virulence gene Ave1. Assignment to the two large clusters 1 and 2 exhibited an almost perfect 1:1 association with races 1 and 2, respectively, except for a single genotype belonging to cluster 2 . Several explanations for this association could be tested in future work. First, these results could suggest that there are two main $V$. dahliae populations that are genetically distinct, relatively homogeneous, and fixed for race 1 or 2 that serve as sources for the ongoing, nondiscrete introduction of inoculum into Lebanon. Alternatively, the population structure observed in Lebanon could be the result of founder effects from a limited number of introductions from various types of source population(s), which have then undergone amplification and some diversification into two main clonal lineages. This latter proposed hypothesis is supported by the clustering pattern in the minimum spanning network in which several MLGs represented by only one to a few isolates each are closely related to the abundant G43 and G13.

Because these two clusters and races were distributed among both crops and all three regions of Lebanon, there are likely active mechanisms that have prevented gene flow between the two race groups. These mechanisms could include a lack of sexual reproduction, which has never been reported for $V$. dahliae, and vegetative incompatibility. The existence of vegetative compatibility groups (VCGs) within populations of pathogens can contribute to genetic drift and differentiation and are thought to limit gene flow among fungal populations (Leslie 1993). V. dahliae isolates in different VCGs have long been considered as genetically isolated populations varying in ecological, physiological, and virulence traits (Katan 2000). Outside its recognition by host $\mathrm{R}$ genes, Ave 1 is a virulence factor for $V$. dahliae because it provides higher quantitative disease-causing ability to isolates infecting a host lacking Vel or a homolog compared with isolates without Avel (de Jonge et al. 2012). The concentration of race 1 into one clonal lineage is consistent with the proposed origin of the race 1 trait. There is strong evidence that $V$. dahliae acquired Avel from plants by horizontal gene transfer from a single event (de Jonge et al. 2012), and with few exceptions race 1 isolates have been shown to be restricted to a single clonal lineage delimited by VCG 2A (Jiménez-Díaz et al. 2017; Rafiei et al. 2018). A similar pattern has been observed for a second type of pathogenic variation in $V$. dahliae, the ability of isolates to cause a severe defoliation symptom of cotton, okra, and olive (Jiménez-Díaz et al. 2012; Schnathorst and Mathre 1966), which is found only within the VCG 1A clonal lineage (Jiménez-Diaz et al. 2017; Milgroom et al. 2016). Thus, the presence of Avel or the association of an isolate with the VCG 1A or 2A clonal lineage can serve as a marker for elevated virulence of $V$. dahliae in selected hosts or host genotypes (JiménezDiaz et al. 2017; Rafiei et al. 2018).

Table 7. Allelic diversity of Verticillium dahliae isolates from Lebanon using full and multilocus haploid genotype plus metadata (MLG+meta) datasets

\begin{tabular}{|c|c|c|c|c|c|c|c|c|c|c|}
\hline \multirow[b]{3}{*}{ Factor } & \multirow[b]{3}{*}{ Group } & \multicolumn{5}{|c|}{ Full } & \multicolumn{4}{|c|}{ MLG+meta } \\
\hline & & \multirow[b]{2}{*}{ Isolates } & \multicolumn{2}{|c|}{ Richness $^{a}$} & \multicolumn{2}{|c|}{ Heterogeneity ${ }^{\mathbf{b}}$} & \multirow[b]{2}{*}{ MLG + meta ${ }^{c}$} & \multirow{2}{*}{$\frac{\text { Richness }^{\mathrm{a}}}{\mathrm{A}_{\mathrm{R}}}$} & \multicolumn{2}{|c|}{ Heterogeneity ${ }^{b}$} \\
\hline & & & $\mathbf{A}_{\mathbf{R}}$ & $\mathbf{N}_{\mathrm{p}}$ & $\mathbf{I}$ & $\mathbf{N}_{\mathrm{e}}$ & & & I & $\mathbf{N}_{\mathrm{e}}$ \\
\hline \multirow[t]{3}{*}{ Host } & Olive & 71 & 38.4 & 13 & $0.67(0.12)^{\mathrm{d}}$ & $1.87(0.15)$ & 37 & 37.9 & $0.77(0.14)$ & $2.09(0.20)$ \\
\hline & Potato & 115 & 43.3 & 27 & $0.47(0.06)$ & $1.32(0.05)$ & 42 & 48.3 & $0.81(0.10)$ & $1.84(0.16)$ \\
\hline & Total & 186 & - & - & $0.57(0.07)$ & $1.59(0.10)$ & 79 & - & $0.79(0.08)$ & $1.96(0.13)$ \\
\hline \multirow[t]{4}{*}{ Race } & 1 & 55 & 14.7 & 23 & $0.25(0.05)$ & $1.13(0.03)$ & 28 & 15.9 & $0.41(0.08)$ & $1.28(0.07)$ \\
\hline & 2 & 125 & 14.9 & 9 & $0.30(0.06)$ & $1.14(0.03)$ & 46 & 17.7 & $0.63(0.11)$ & $1.50(0.13)$ \\
\hline & Missing & 6 & 23.9 & 2 & $0.64(0.05)$ & $1.70(0.08)$ & 5 & 23.1 & $0.71(0.06)$ & $1.87(0.10)$ \\
\hline & Total & 186 & - & - & $0.40(0.04)$ & $1.32(0.05)$ & 79 & - & $0.58(0.05)$ & $1.55(0.07)$ \\
\hline \multirow[t]{5}{*}{ Cluster } & 1 & 53 & 12.6 & 7 & $0.10(0.04)$ & $1.05(0.02)$ & 26 & 13.0 & $0.17(0.07)$ & $1.11(0.05)$ \\
\hline & 2 & 124 & 12.6 & 11 & $0.13(0.05)$ & $1.06(0.02)$ & 44 & 13.6 & $0.28(0.10)$ & $1.20(0.08)$ \\
\hline & 3 & 4 & 13.2 & 9 & $0.10(0.07)$ & $1.12(0.08)$ & 4 & 13.2 & $0.10(0.07)$ & $1.12(0.08)$ \\
\hline & 4 & 5 & 18.7 & 20 & $0.73(0.14)$ & $2.15(0.28)$ & 5 & 18.7 & $0.73(0.14)$ & $2.15(0.28)$ \\
\hline & Total & 186 & & - & $0.27(0.06)$ & $1.34(0.10)$ & 79 & - & $0.32(0.06)$ & $1.40(0.10)$ \\
\hline
\end{tabular}

\footnotetext{
${ }^{a} A_{R}$ : Total allelic richness with rarefaction, $N_{p}$ : number of private alleles. $N_{p}$ was omitted from the MLG+meta dataset because the values are identical to the nonclone corrected dataset.

b I: Shannon's information index, $\mathrm{N}_{\mathrm{e}}$ : mean number of effective alleles.

$\mathrm{c}$ The MLG+meta dataset consisted of clone-correction for the 12 microsatellite loci plus the metadata factors host, geographic region of origin (Bekaa, North, South), and race.

${ }^{\mathrm{d}}$ Value in parentheses represents the standard error of the corresponding mean value.
} 


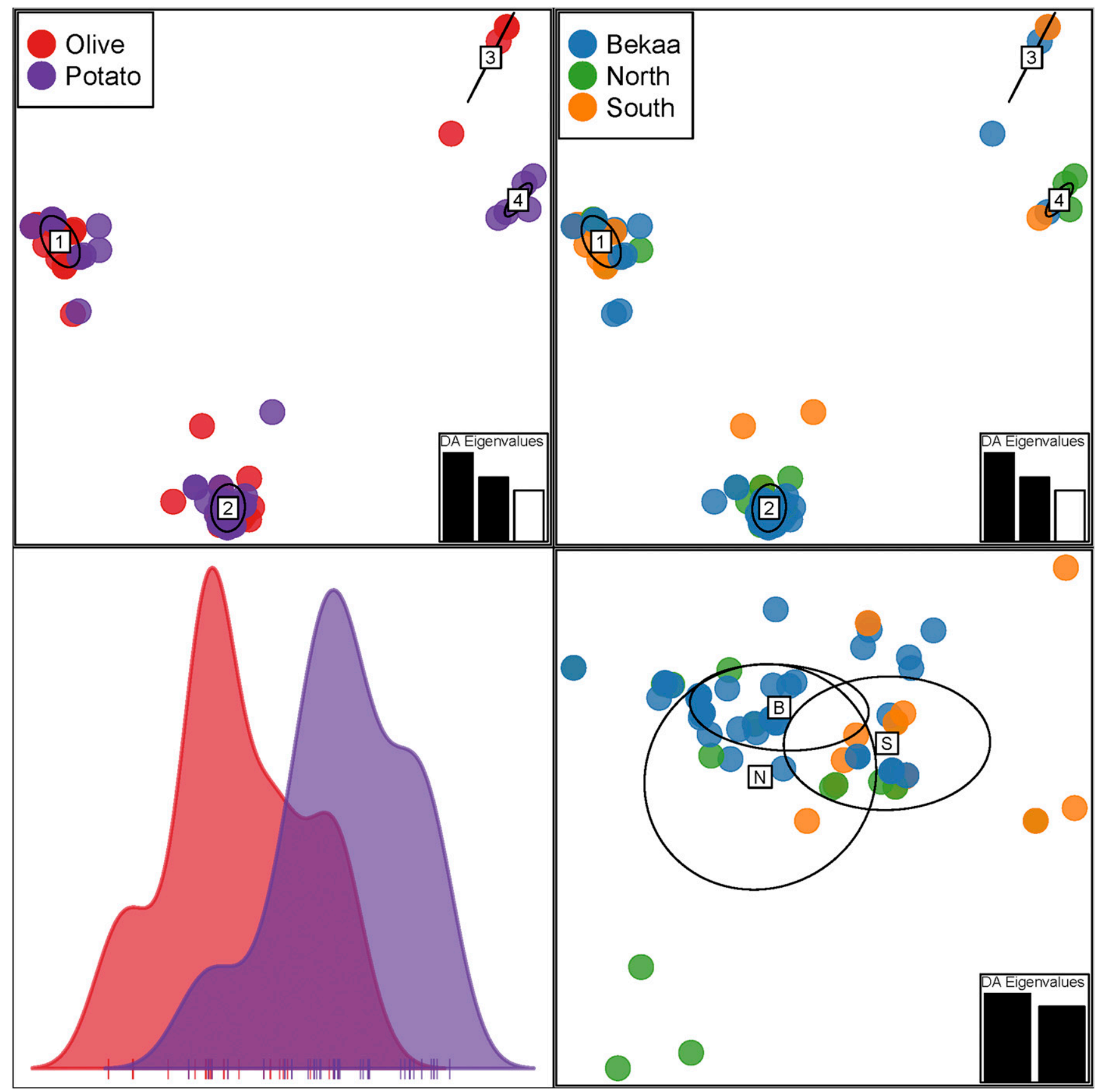

Fig. 3. Association of population structure of Verticillium dahliae with the metadata factors host of origin and region of origin by discriminant analysis of principal components (DAPC). Dataset consisted of 186 isolates after individual (isolates with more than two loci missing) and locus (VD97 removed) quality control steps that was strictly clonecorrected to multilocus genotype and the combined host-region-race factor. Left column of panels: clones identified by host of origin. Right column: geographic region of origin. Top row of panels: Discriminant analysis (DA) was initialized using an unsupervised $k$-means clustering algorithm at $k=4$. Bottom row: DA was initialized using the respective metadata factor. Ellipses represent variation inertia for each cluster (1-4) or metadata group ( $\mathbf{B}=$ Bekaa, $\mathbf{N}=$ northern Lebanon, $\mathbf{S}=$ southern Lebanon). Inset bar charts are scree plots that show eigenvalues of DA axes; shaded bars identify which axes are plotted. The bottom-left panel contains a single dimension density plot because only one DA axis is obtainable from the data.

Table 8. Per-locus estimates of I (information index) within Verticillium dahliae isolates from olive or potato using the multilocus haploid genotype plus metadata (MLG+meta) datasets

\begin{tabular}{|c|c|c|c|c|c|c|c|c|c|c|c|c|c|}
\hline \multirow[b]{2}{*}{ Factor } & \multirow[b]{2}{*}{ Group } & \multicolumn{12}{|c|}{ Locus } \\
\hline & & VD01 & VD02 & VD03 & VD08 & VD09 & VD10 & VD11 & VD12 & VD27 & VD69 & VD73 & VD92 \\
\hline \multirow[t]{3}{*}{ Host } & Olive & 1.121 & 1.061 & 0.000 & 1.284 & 0.684 & 0.922 & 0.000 & 0.965 & 1.172 & 1.022 & 1.008 & 0.000 \\
\hline & Potato & 0.978 & 0.970 & 0.496 & 0.914 & 0.562 & 0.792 & 0.320 & 1.086 & 0.800 & 0.770 & 1.585 & 0.421 \\
\hline & Mean & 1.049 & 1.016 & 0.248 & 1.099 & 0.623 & 0.857 & 0.160 & 1.025 & 0.986 & 0.896 & 1.297 & 0.211 \\
\hline \multirow[t]{4}{*}{ Race } & 1 & 0.531 & 0.574 & 0.168 & 0.980 & 0.469 & 0.630 & 0.000 & 0.315 & 0.315 & 0.420 & 0.499 & 0.000 \\
\hline & 2 & 1.103 & 0.650 & 0.320 & 0.519 & 0.182 & 0.528 & 0.249 & 0.685 & 0.950 & 0.641 & 1.434 & 0.283 \\
\hline & Missing & 0.950 & 0.950 & 0.500 & 0.950 & 0.562 & 0.562 & 0.500 & 0.950 & 0.673 & 0.673 & 0.637 & 0.562 \\
\hline & Mean & 0.861 & 0.725 & 0.329 & 0.816 & 0.404 & 0.573 & 0.250 & 0.650 & 0.646 & 0.578 & 0.856 & 0.282 \\
\hline
\end{tabular}


On a broader scale than these two factors, numerous reports have documented host adaptation within $V$. dahliae, in which isolates cause quantitatively more disease in their host of origin compared with other hosts (Bhat and Subbarao 1999). Several of these studies found that the host adaptation was correlated with isolate VCG (Berbegal et al. 2010; Douhan and Johnson 2001; Dung et al. 2013a; Jiménez-Díaz et al. 2006; Korolev et al. 2000). V. dahliae isolates infecting olive have so far been found to belong to VCG1A, VCG2A, VCG2B, and VCG4B (Dervis et al. 2010; Navas-Cortés et al. 2009). In contrast, the majority of $V$. dahliae isolates associated with potato are in VCGs 4A and 4B (Joaquim and Rowe 1991; Strausbaugh 1993). Characterizing the virulence of our isolates, including for the defoliating/nondefoliating pathotype, was beyond the scope of this study. However, because isolate VCG strongly correlates with molecular markers (Milgroom et al. 2016), host adaptation may contribute to population structure as inferred by molecular markers.

The combined effect of race and host adaptation may have combined to create the moderate association of genetic structure with host that we observed in this study. The two races were distributed almost equally within isolates from olive but were skewed approximately 1: 2 toward race 2 among isolates from potato. This skewed distribution of races among hosts is roughly similar to the distribution of genetic clusters among hosts, and may be explained by the gene-for-gene interaction between pathogen and hosts. Homologs to Vel are present in potato (Song et al. 2016), and the planting of cultivars that possess a $V e 1$ homolog would exert a selection pressure on $V$. dahliae from potato to shift toward race 2 isolates which lack Ave1 and thus evade detection by $\mathrm{Ve} 1$ homologs. Similarly, repeated cultivation of a crop may select for $V$. dahliae strains adapted to that host. These selection pressures could explain the moderate association of genetic structure with host and may confound further inference of population genetic forces such as gene flow.

An alternative proposed hypothesis for future testing is that the genetic structure-host association is due to differences between the crops in propagation practices and geographic production patterns. Material for planting potato in Lebanon can originate from certified seed tubers from the European Union or locally produced tubers that in turn originated from Europe. These activities could be providing mechanisms for the introduction and dissemination of new genotypes of $V$. dahliae. Certified seed tubers imported to Lebanon (Saad et al. 2004), certified seed tubers for use in the United States (Dung et al. 2013b), and uncertified tuber seeds obtained from fields in Akkar, Lebanon (Baroudy et al. 2016) have been shown to be infected by $V$. dahliae. In contrast, olive seedlings had been locally produced until the recent introduction of foreign varieties. In addition to propagation practices, olive and potato have historically been grown in separate geographic regions of Lebanon. However, longtime potato-growing fields in the Bekaa area have recently been planted with olive. Indeed, of 12 MLG (excluding G43) representing olive isolates and belonging to cluster 2 (which is skewed toward potato), nine represent isolates obtained exclusively from the Bekaa area.

Genetic structure was also weakly associated with the isolate's geographic region of origin and is almost entirely due to differentiation of isolates from the South, where 24 of the 28 isolates were obtained from olive, when compared with the Bekaa area. Olive trees

Table 9. Pairwise fixation of Verticillium dahliae isolates among geographic regions estimated by $\Phi_{\text {PT }}$ in an analysis of molecular variance framework from the multilocus haploid genotype plus metadata (MLG+meta) datasets

\begin{tabular}{lccc}
\hline & & \multicolumn{1}{c}{$\boldsymbol{\Phi}_{\mathbf{P T}} \backslash \boldsymbol{P}$-value } \\
\cline { 3 - 3 } Area & Bekaa & North & South \\
\hline Bekaa & - & 0.018 & 0.002 \\
North & 0.080 & - & 0.205 \\
South & 0.186 & 0.034 & - \\
\hline
\end{tabular}

${ }^{\text {a }} \Phi_{\text {PT }}$ (below diagonal): Distance-based fixation index standardized for mean within-population diversity. $P$ value (above diagonal): evaluation of $\Phi_{\text {PT }}$ against the null hypothesis of no difference between populations using 999 permutations. have been planted for hundreds of years in Lebanon (Chalak et al. 2015), and they are cultivated on a greater geographical scale and in more microclimates than potato. In addition, the higher diversity of $V$. dahliae subpopulation isolated from olive compared with potato could partially be explained by the longer cultivation history.

This research found that the population of $V$. dahliae in Lebanon is dominated by two clonal lineages that are fixed for either race 1 or race 2. Because genetic diversity is generally well distributed geographically throughout Lebanon and among two major hosts, measures that focus on reducing the introduction of new genotypes via foreign inoculum may limit the ability of the endemic $V$. dahliae population to increase in virulence, damage other hosts, or adapt to management measures.

\section{Literature Cited}

Adamack, A. T., and Gruber, B. 2014. PopGenReport: Simplifying basic population genetic analyses in R. Methods Ecol. Evol. 5:384-387.

Anonymous, 2012. Résultats Globaux du Module de Base du Recensement de L'Agriculture 2010. Projet "Observatoire Libanais de Développement Agricole".

Arnaud-Haond, S., Duarte, C. M., Alberto, F., and Serrão, E. A. 2007. Standardizing methods to address clonality in population studies. Mol. Ecol. 16:5115-5139.

Baroudy, F., Habib, W., Puri, K., Al Sabbagh, C., Subbarao, K. V., and Nigro, F. 2016. Verticillium dahliae: The main cause of potato wilt in Lebanon. Page 48 in: (Abstr.) 12th Int. Verticillium Symp. Ljubljana, Slovenia.

Berbegal, M., Ortega, A., Jiménez-Gasco, M. M., Olivares-García, C., JiménezDíaz, R. M., and Armengol, J. 2010. Genetic diversity and host range of Verticillium dahliae isolates from artichoke and other vegetable crops in Spain. Plant Dis. 94:396-404.

Bhat, R. G., and Subbarao, K. V. 1999. Host range specificity in Verticillium dahliae. Phytopathology 89:1218-1225.

Brewer, C. A. 2013. http://colorbrewer2.org. Accessed 19 February 2018.

Briatte, F. 2016. ggnetwork: Geometries to plot networks with 'ggplot2'. R package version 0.5.1. https://CRAN.R-project.org/web/packages/ggnetwork/ index.html

Bruvo, R., Michiels, N. K., D’Souza, T. G., and Schulenburg, H. 2004. A simple method for the calculation of microsatellite genotype distances irrespective of ploidy level. Mol. Ecol. 13:2101-2106.

Chalak, L., Haouane, H., Essalouh, L., Santoni, S., Besnard, G., and Khadari, B. 2015. Extent of the genetic diversity in Lebanese olive (Olea europaea L.) trees: A mixture of an ancient germplasm with recently introduced varieties. Genet. Resour. Crop Evol. 62:621-633.

Chao, A., Chiu, C.-H., and Jost, L. 2014. Unifying species diversity, phylogenetic diversity, functional diversity, and related similarity and differentiation measures through Hill numbers. Annu. Rev. Ecol. Evol. Syst. 45:297-324.

Chao, A., Jost, L., Hsieh, T. C., Ma, K. H., Sherwin, W. B., and Rollins, L. A. 2015. Expected Shannon entropy and Shannon differentiation between subpopulations for neutral genes under the finite island model. PLoS One 10: e0125471.

Csardi, G., and Nepusz, T. 2006. The igraph software package for complex network research. InterJournal Complex Systems:1695. http://igraph.org.

de Jonge, R., van Esse, H. P., Maruthachalam, K., Bolton, M. D., Santhanam, P. Saberm, M. K., Zhang, Z., Usami, T., Lievens, B., Subbarao, K. V., and Thomma, B. P. H. J. 2012. Tomato immune receptor Ve1 recognizes effector of multiple fungal pathogens uncovered by genome and RNA sequencing. Proc. Natl. Acad. Sci. USA 109:5110-5115.

Dervis, S., Mercado-Blanco, J., Erten, L., Valverde-Corredor, A., and Pérez-Artés, E. 2010. Verticillium wilt of olive in Turkey: A survey on disease importance, pathogen diversity and susceptibility of relevant olive cultivars. Eur. J. Plant Pathol. 127:287-301.

Dorken, M. E., and Eckert, C. G. 2001. Severely reduced sexual reproduction in northern populations of a clonal plant, Decodon verticillatus (Lythraceae). J. Ecol. 89:339-350.

Douhan, L. I., and Johnson, D. A. 2001. Vegetative compatibility and pathogenicity of Verticillium dahliae from spearmint and peppermint. Plant Dis. 85:297-302.

Dung, J. K. S., Hamm, P. B., Eggers, J. E., and Johnson, D. A. 2013b. Incidence and impact of Verticillium dahliae in soil associated with certified potato seed lots. Phytopathology 103:55-63.

Dung, J. K. S., Peever, T. L., and Johnson, D. A. 2013a. Verticillium dahliae populations from mint and potato are genetically divergent with predominant haplotypes. Phytopathology 103:445-459.

Ellison, A. M. 2010. Partitioning diversity. Ecology 91:1962-1963.

Ellstrand, N. C., and Roose, M. L. 1987. Patterns of genotypic diversity in clonal plant-species. Am. J. Bot. 74:123-131.

Excoffier, L., Smouse, P. E., and Quattro, J. M. 1992. Analysis of molecular variance inferred from metric distances among DNA haplotypes: Application to human mitochondrial DNA restriction data. Genetics 131:479-491. 
FAOSTAT. 2014. Food and Agriculture Organization of the United Nations Statistics Division, http://faostat.fao.org/en/\#home Accessed 19 February 2018.

Fick, G., and Zimmer, D. 1974. Monogenic resistance to Verticillium wilt in sunflowers. Crop Sci. 14:895-896.

Gurung, S., Short, D. P. G., Atallah, Z. K., and Subbarao, K. V. 2014. Clonal expansion of Verticillium dahliae in lettuce. Phytopathology 104:641-649.

Habib, W., Choueiri, E., Baroudy, F., Tabet, D., Gerges, E., Saab, C., and Nigro, F. 2017. Soil inoculum density of Verticillium dahliae and Verticillium wilt of olive in Lebanon. Ann. Appl. Biol. 170:150-159.

Hayes, R. J., McHale, L. K., Vallad, G. E., Truco, M. J., Michelmore, R. W., Klosterman, S. J., Maruthachalam, K., and Subbarao, K. V. 2011. The inheritance of resistance to Verticillium wilt caused by race 1 isolates of Verticillium dahliae in the lettuce cultivar La Brillante. Theor. Appl. Genet. 123:509-517.

Inderbitzin, P., Davis, R. M., Bostock, R. M., and Subbarao, K. V. 2011. The Ascomycete Verticillium longisporum is a hybrid and a plant pathogen with an expanded host range. PLoS One 6:e18260.

Inderbitzin, P., Davis, R. M., Bostock, R. M., and Subbarao, K. V. 2013. Identification and differentiation of Verticillium species and V. longisporum lineages by simplex and multiplex PCR assays. PLoS One 8:e65990.

Inderbitzin, P., and Subbarao, K. V. 2014. Verticillium systematics and evolution: How confusion impedes Verticillium wilt management and how to resolve it. Phytopathology 104:564-574.

Jiménez-Díaz, R. M., Cirulli, M., Bubici, G., Jiménez-Gasco, M. M., Antoniou, P. P., and Tjamos, E. C. 2012. Verticillium wilt, a major threat to olive production: Current status and future prospects for its management. Plant Dis. 96:304-329.

Jiménez-Díaz, R. M., Mercado-Blanco, J., Olivares-García, C., Collado-Romero, M., Bejarano-Alcázar, J., Rodríguez-Jurado, D., Giménez-Jaime, A., GarcíaJiménez, J., and Armengol, J. 2006. Genetic and virulence diversity in Verticillium dahliae populations infecting artichoke in Eastern-Central Spain. Phytopathology 96:288-298.

Jiménez-Díaz, R. M., Olivares-García, C., Trapero-Casas, J. L., Jiménez-Gasco, M. M., Navas Cortés, J. A., Landa, B. B., and Milgroom, M. G. 2017. Variation of pathotypes and races and their correlations with clonal lineages in Verticillium dahliae. Plant Pathol. 66:651-666.

Joaquim, T. R., and Rowe, R. C. 1991. Vegetative compatibility and virulence of strains of Verticillium dahliae from soil and potato plants. Phytopathology 81:552-558

Jombart, T. 2008. adegenet: A R package for the multivariate analysis of genetic markers. Bioinformatics 24:1403-1405.

Jombart, T., and Ahmed, I. 2011. adegenet 1.3-1: New tools for the analysis of genome-wide SNP data. Bioinformatics 27:3070-3071.

Jombart, T., Devillard, S., and Balloux, F. 2010. Discriminant analysis of principal components: A new method for the analysis of genetically structured populations. BMC Genet. 11:94.

Kamvar, Z. N., Brooks, J. C., and Grünwald, N. J. 2015. Novel R tools for analysis of genome-wide population genetic data with emphasis on clonality. Front. Genet. 6:208.

Kamvar, Z. N., Tabima, J. F., and Grünwald, N. J. 2014. Poppr: An R package for genetic analysis of populations with clonal, partially clonal, and/or sexual reproduction. PeerJ 2:e281.

Katan, T. 2000. Vegetative compatibility in populations of Verticillium - an overview. Advances in Verticillium Research and Disease Management. E. C. Tjamos, R. C. Rowe, J. B. Heale, and R. D. Fravel, eds. American Phytopathological Society, St. Paul, MN.

Korolev, N., Katan, J., and Katan, T. 2000. Vegetative compatibility groups of Verticillium dahliae in Israel: Their distribution and association with pathogenicity. Phytopathology 90:529-536.

Leslie, J. F. 1993. Fungal vegetative compatibility. Annu. Rev. Phytopathol. 31: 127-150.

Meirmans, P. G. 2006. Using the AMOVA framework to estimate a standardized genetic differentiation measure. Evolution 60:2399-2402.

Michalakis, Y., and Excoffier, L. 1996. A generic estimation of population subdivision using distanced between alleles with special reference for microsatellite loci. Genetics 142:1061-1064

Milgroom, M. G., Jiménez-Gasco, M. M., Olivares-García, C., and Jiménez-Díaz, R. M. 2016. Clonal expansion and migration of a highly virulent, defoliating lineage of Verticillium dahliae. Phytopathology 106:1038-1046.

Molecular Ecology Resources Primer Development Consortium, Atallah, Z. K., Maruthachalam, K. K., Davis, R. M., Klosterman, S. J., Subbarao, K. V., et al. Permanent genetic resources added to molecular ecology resources database 1 May 2009-31 July. 2009. Mol. Ecol. Resour. 9:1460-1466.

Navas-Cortés, J. A., Olivares, C., Trapero-Casas, J. L., Landa, B. B., JiménezGasco, M. M., and JiménezDíaz, R. M. 2009. The influence of agronomic factors on prevalence and distribution of Verticillium dahliae vegetative compatibility groups and pathotypes infecting olive in Andalusia, southern Spain. Page 79 in: (Abstr.) 10 ${ }^{\text {th }}$ Int. Verticillium Symp. Corfu, Greece.

Neuwirth, E. 2014. RColorBrewer: ColorBrewer Palettes. R package version 1.12. https://CRAN.R-project.org/web/packages/RColorBrewer/index.html

Nychka, D., Furrer, R., Paige, J., and Sain, S. 2015. Fields: Tools for spatial data. University Corporation for Atmospheric Research, Boulder, CO.
Peakall, R., and Smouse, P. E. 2006. GenAlEx 6: Genetic analysis in Excel Population genetic software for teaching and research. Mol. Ecol. Notes 6: 288-295.

Peakall, R., and Smouse, P. E. 2012. GenAlEx 6.5: Genetic analysis in Excel. Population genetic software for teaching and research-an update. Bioinformatics 28:2537-2539.

Pegg, G. F., and Brady, B. L., eds. 2002. Verticillium Wilts. CABI Publishing, Wallingford, Oxon, UK.

Puri, K. D., Gurung, S., Short, D. P. G., Atallah, Z. K., Sandoya, G., Michael Davis, R., Hayes, R. J., and Subbarao, K. V. 2017. Short-term host selection pressure has little effect on the evolution of a monoclonal population of Verticillium dahliae Race 1. Phytopathology 107:1417-1425.

$\mathrm{R}$ Core Team. 2016. A language and environment for statistical computing. $\mathrm{R}$ Foundation for Statistical Computing, Vienna, Austria. https://www.Rproject.org/.

Rafiei, V., Banihashemi, Z., Jiménez-Díaz, R. M., Navas-Cortés, J. A., Landa, B. B., Jiménez-Gasco, M. M., Turgeon, B. G., and Milgroom, M. G. 2018. Comparison of genotyping by sequencing and microsatellite markers for unravelling population structure in the clonal fungus Verticillium dahliae. Plant Pathol. 67:76-86.

Saad, A. T., Hanna, L., Abi Ghanem, R., and Choueiri, E. 2004. Fungus diseases on certified seed potato tubers. (Abstr.) Phytopathology 94:S90.

Schliep, K. P. 2011. phangorn: Phylogenetic analysis in R. Bioinformatics 27: 592-593.

Schnathorst, W. C., and Mathre, D. E. 1966. Host range and differentiation of a severe form of Verticillium albo-atrum in cotton. Phytopathology 56:1155-1161.

Sherwin, W. B., Chao, A., Jost, L., and Smouse, P. E. 2017. Information theory broadens the spectrum of molecular ecology and evolution. Trends Ecol. Evol. 32:948-963.

Sherwin, W. B., Jabot, F., Rush, R., and Rossetto, M. 2006. Measurement of biological information with applications from genes to landscapes. Mol. Ecol 15:2857-2869.

Short, D. P. G., Gurung, S., Gladieux, P., Inderbitzin, P., Atallah, Z. K., Nigro, F., Li, G., Benlioglu, S., and Subbarao, K. V. 2015. Globally invading populations of the fungal plant pathogen Verticillium dahliae are dominated by multiple divergent lineages. Environ. Microbiol. 17:2824-2840.

Short, D. P. G., Gurung, S., Maruthachalam, K., Atallah, Z. K., and Subbarao, K. V. 2014. Verticillium dahliae race 2 -specific PCR reveals a high frequency of race 2 strains in commercial spinach seed lots and delineates race structure. Phytopathology 104:779-785.

Simko, I., Costanzo, S., Haynes, K. G., Christ, B. J., and Jones, R. W. 2003. Identification of molecular markers linked to the Verticillium wilt resistance gene homologue in potato (Solanum tuberosum L.). Acta Hortic.: 127-133.

Smouse, P. E., Whitehead, M. R., and Peakall, R. 2015. An informational diversity framework, illustrated with sexually deceptive orchids in early stages of speciation. Mol. Ecol. Resour. 15:1375-1384.

Song, Y., Zhang, Z., Seidl, M. F., Majer, A., Jakse, J., Javornik, B., and Thomma, B. P. H. J. 2016. Broad taxonomic characterization of Verticillium wilt resistance genes reveals ancient origin of the tomato Ve1 immune receptor. Mol. Plant Pathol. 18:195-209.

Strausbaugh, C. A. 1993. Assessment of vegetative compatibility and virulence of Verticillium dahliae isolates from Idaho potatoes and tester strains. Phytopathology 83:1253-1258.

Usami, T., Itoh, M., and Amemiya, Y. 2009. Asexual fungus Verticillium dahliae is potentially heterothallic. J. Gen. Plant Pathol. 75:422-427.

Wickham, H. 2011. The split-apply-combine strategy for data analysis. J. Stat Softw. 40:1-29.

Wickham, H. 2016. Tidyr: easily tidy data with 'spread()' and 'gather()' functions. R package version 0.6.0. https://CRAN.R-project.org/web/packages/tidyr/index. html

Wickham, H. 2018. stringr: Simple, consistent wrappers for common string operations. R package version 1.3.1. https://CRAN.R-project.org/web/packages/ stringr/index.html

Wickham, H., and Francois, R. 2016. dplyr: A grammar of data manipulation. R package version 0.5.0. https://CRAN.R-project.org/web/packages/dplyr/index. html

Wilhelm, S. 1955. Longevity of the Verticillium wilt fungus in the laboratory and field. Phytopathology 45:180-181

Wilke, C. O. 2018. cowplot: Streamlined plot theme and plot annotations for 'ggplot2'. R package version 0.9.3. https://CRAN.R-project.org/web/packages/ cowplot/index.html

Yu, G. 2018. scatterpie: Scatter pie plot. R package version 0.1.2. https://CRAN.Rproject.org/web/packages/scatterpie/index.html

Yu, G., Smith, D., Zhu, H., Guan, Y., and Lam, T. T. 2017. ggtree: An R package for visualization and annotation of phylogenetic trees with their covariates and other associated data. Methods Ecol. Evol. 8:28-36.

Zhang, Z., van Esse, H. P., van Damme, M., Fradin, E. F., Liu, C.-M., and Thomma, B. P. H. J. 2013. Ve1-mediated resistance against Verticillium does not involve a hypersensitive response in Arabidopsis. Mol. Plant Pathol. 14 719-727. 